NBER WORKING PAPER SERIES

\title{
RATIONING THE COMMONS
}

\author{
Nicholas Ryan \\ Anant Sudarshan \\ Working Paper 27473 \\ http://www.nber.org/papers/w27473 \\ NATIONAL BUREAU OF ECONOMIC RESEARCH \\ 1050 Massachusetts Avenue \\ Cambridge, MA 02138 \\ July 2020
}

We thank the National Science Foundation (SES-1919076), the Payment and Government Research Program of J-PAL South Asia, the NBER Future of Energy Distribution program and the Shakti Sustainable Energy Foundation for financial support. We thank Rajasthan Rajya Vidhyut Prasaran Nigam (RVPN) and Jaipur Vidyut Vitran Nigam Limited (JVVNL) for cooperation in sharing data. We thank Aditi Gupta, Ameek Singh, Bhavya Srivastava, Vivek Singh Grewal, Hamza Mohammad Syed, Viraj Jorapur and Yashaswi Mohanty for excellent research assistance. We thank Jose-Antonio Espın-Sanchez, Kelsey Jack, Matthew Kotchen, Benjamin Olken, Gerard Padro i Miquel, Rohini Pande, Steven Puller and Duncan Thomas for comments. The views expressed herein are those of the authors and do not necessarily reflect the views of the National Bureau of Economic Research.

NBER working papers are circulated for discussion and comment purposes. They have not been peerreviewed or been subject to the review by the NBER Board of Directors that accompanies official NBER publications.

(C) 2020 by Nicholas Ryan and Anant Sudarshan. All rights reserved. Short sections of text, not to exceed two paragraphs, may be quoted without explicit permission provided that full credit, including $\odot$ notice, is given to the source. 
Rationing the Commons

Nicholas Ryan and Anant Sudarshan

NBER Working Paper No. 27473

July 2020

JEL No. D24,O13,Q15,Q56

\begin{abstract}
$\underline{\text { ABSTRACT }}$
Common resources may be managed with inefficient policies for the sake of equity. We study how rationing the commons shapes the efficiency and equity of resource use, in the context of agricultural groundwater use in Rajasthan, India. We find that rationing binds on input use, such that farmers, despite trivial prices for water extraction, use roughly the socially optimal amount of water on average. The rationing regime is still grossly inefficient, because it misallocates water across farmers, lowering productivity. Pigouvian reform would increase agricultural surplus by $12 \%$ of household income, yet fall well short of a Pareto improvement over rationing.
\end{abstract}

Nicholas Ryan

Department of Economics

Yale University

P. O. Box 208269

New Haven, CT 06520

and NBER

nicholas.ryan@yale.edu

Anant Sudarshan

Department of Economics and

Energy Policy Institute at Chicago

University of Chicago

Saieh Hall

5757 S. University Avenue

Chicago, IL 60637

anants@uchicago.edu

A data appendix is available at http://www.nber.org/data-appendix/w27473 


\section{Introduction}

Our economic ideals for managing common resources do not seem to be widely used. Pricing the social costs of resource use, or laying down clear property rights, can each lead to the efficient use of the commons (Pigou, 1932; Coase, 1960). Despite the efficiency and generality of these policies, they are often not put into practice, even as many common resources around the globe are being depleted (Daily et al., 2000; Walker et al., 2009; Newell, Pizer and Raimi, 2014).

A main reason why these ideal regimes may not be adopted is their neglect for equity among users of the commons. At a local scale, the institutions that succeed in governing the commons balance efficiency and equity (Ostrom, 1990). But these local institutions cannot scale to meet large commons problems with heterogeneous users (Dietz, Ostrom and Stern, 2003; Ostrom, 2009). Economic ideals, by contrast, maintain their efficiency for large problems, but fail the politics of equity, since market-based allocation threatens to leave many users of the commons worse off (Jackson, 2018). The result is that for large problems, which outstrip governing the commons in the sense of Ostrom, we are left either with laissez faire, or with rationing the commons: setting coarse rules to ensure that access to the commons will be fair, if not efficient. ${ }^{1}$

The widespread use of such rules raises questions of longstanding interest. ${ }^{2}$ How well is the rule actually in use being set? What is the loss, in practice, from using such a rule instead of market-based allocation? And what are the constraints that have led policy to favor rules over markets?

This paper studies the trade-off between efficiency and equity in the management of the Indian groundwater commons. Farmers use groundwater to irrigate their crops. Massive growth

\footnotetext{
${ }^{1}$ Examples of rationing or ration-like instruments arise for a diverse set of commons problems. Rationing is used to allocate water for domestic use during droughts (Mansur and Olmstead, 2012; Lund and Reed, 1995) and is also used to allocate energy during crises (Maxwell and Balcom, 1946; Olmstead and Rhode, 1985; Frech III and Lee, 1987). Some sources of energy have been subject to price caps and therefore rationing over long periods of time (Davis and Kilian, 2011). Rations for irrigation water are imposed either explicitly as quotas or through allocations of rights with limited transferability (Ostrom, 1991; Ostrom and Gardner, 1993; Gardner, Moore and Walker, 1997; Libecap, 2011; Donna and Espin-Sanchez, 2018). Some developing countries set non-transferable quotas for timber extraction (Baird, 2010; Burgess et al., 2012). Rations allocated via lotteries are used for recreation and hunting rights to protect the wilderness (Stankey, 1979; Ohler, Chouinard and Yoder, 2007; Scrogin, Berrens and Bohara, 2000) and driving rights to improve air quality and reduce congestion (Davis, 2008; Viard and Fu, 2015; Li, 2017).

${ }^{2}$ Coase himself acknowledged the gap between ideal policies and those actually used, writing that ". . . whatever we may have in mind as our ideal world, it is clear that we have not yet discovered how to get to it from where we are. A better approach would seem to be to start our analysis with a situation approximating that which actually exists, to examine the effects of a proposed policy change, and to attempt to decide whether the new situation would be, in total, better or worse than the original one." (Coase, 1960)
} 
in groundwater access has profited millions of small farmers and made up a large part of India's gains in agricultural yields since the Green Revolution (Murgai, 1999; Murgai, Ali and Byerlee, 2001). India is now the largest user of groundwater in the world, extracting more in a year than the United States and China combined (National Ground Water Association, 2016). The cost of this long boom has been a corresponding depletion of natural capital, with a rate of groundwater decline faster, in parts of India, than anywhere else in the world (Famiglietti, 2014; Lo et al., 2016).

The institution that has arisen to manage India's groundwater use, contrary to both the Coasean and Pigouvian ideals, is rationing. Groundwater has no price and property rights over groundwater are not defined. Instead of pricing electricity, which is used to extract groundwater, above private cost, to account for the social cost of groundwater use, Indian states price electricity at or near zero, but then ration the supply of power to farmers to limit their groundwater use. The states that have adopted this regime have a combined population of 585 million people (365 million in rural areas) and produce $65 \%$ of the country's agricultural output, making rationing the de facto groundwater policy for the world's largest user.

We study rationing in three parts, one theoretical and two empirical. First, we model agricultural production under rationing and derive a formula for the optimal ration. Second, we use a marginal analysis, often called a "sufficient statistics" approach, to judge the efficiency of the status quo ration. Third, we estimate the production model and use it to study the counterfactual results of replacing rationing with Pigouvian pricing.

The first part is a model of agricultural production using groundwater. Farmers are heterogeneous in productivity and in factor endowments. Under rationing, power has a nominal price and groundwater no price. The market therefore clears on quantity, set by the ration of power, and not price. An efficient ration balances two forces: the marginal social benefit of increasing the ration, which raises profit for farmers, against the marginal social cost, which includes the unpriced cost of electricity used for pumping and the opportunity cost of water. The main result from the model is that a ration, even one that is set to maximize social surplus, distorts the allocation of water and lowers surplus, and this loss grows the greater is dispersion in productivity. Productive farmers use too little water, since they are constrained by the ration; unproductive farmers use too much, due to the low price of power.

To carry out the empirical parts, we ran a large, original agricultural household survey of 
farmers in the state of Rajasthan, India, which has the fastest groundwater depletion in the world (Famiglietti, 2014; Lo et al., 2016). The survey was designed to have both broad geographic coverage of groundwater conditions and the needed level of detail, on irrigation practices, to relate agricultural production to the rationing policy.

The second part of the analysis then estimates the marginal benefit of increasing the ration and uses this estimate to judge the efficiency of the status quo ration. Measuring the marginal benefit of increasing the ration poses an empirical challenge. The ration does not vary, so it is not possible directly to estimate the effects of a change in the ration. Moreover, under a binding ration, the quantity of power that a farmer uses does not reflect their marginal willingness-to-pay for power and water. We show that the ration binds: every farmer gets only 6 hours of electricity per day and uses nearly that amount. ${ }^{3}$ Therefore it is also not possible to estimate the marginal benefit of power use by revealed preference, using farmer demand for electricity.

Our model suggests an alternative way of estimating the marginal benefit of increasing the ration. The key idea is that, in our setting, electricity is useful as an input only as a means to extract water. The marginal return to water is therefore a sufficient statistic for the benefit of an increased electricity ration. We use plausibly exogenous variation in groundwater conditions, based on the geology of aquifers, to estimate farmers' returns to water. We then plug-in this sufficient statistic to calculate the implied return to increasing the electricity ration. In this way, we use variation in groundwater depth to mimic the effects of (non-existent) variation in the ration.

The main result of the marginal analysis is that the status quo ration, six hours per day, is roughly socially optimal, or somewhat too high. Since the external cost of water use is a pure opportunity cost, such a judgment depends on the discount factor. We estimate that, for a discount factor of $\beta=0.90$, the marginal benefit of increasing the ration is above the private marginal cost of power, but somewhat less than the social marginal cost. We calculate that a discount factor of $\beta=0.82$ would rationalize the observed level of the ration as socially efficient, among uniform rationing regimes.

This finding contradicts the common parable about agricultural groundwater use in India:

\footnotetext{
${ }^{3}$ If the government rationed electricity only on this intensive margin of hours of supply, then it would be possible to evade the ration by increasing the size of one's pump or the number of pumps connected to the grid. We observe that the government also rations farmers on these extensive margins, so that the binding intensive margin ration does effectively limit farmers' power and water use.
} 
electricity prices are far too low, so farmers must use too much water (Kumar and Singh, 2001; Shah, Giordano and Mukherji, 2012; Famiglietti, 2014; Zhang, 2019). This view assumes that the market is clearing on price, in which case water use must be too high, because price is so far below social cost (about $7 \%$ of social cost, by our estimates). We show that the market instead clears on quantity, which renders the efficiency of observed water use an empirical question: water use may be too high or too low, depending on farmers' returns to water. We estimate that the ration limits water use to a level that is, on average, about right.

While the marginal approach allows us to judge the status quo ration, it cannot speak to how rationing compares to other policy regimes. The third part of the paper therefore estimates a structural model of agricultural production under rationing and applies the model to study counterfactual policies to manage the commons.

The structural estimates and counterfactuals yield two main findings. First, though the ration is set at a roughly efficient level, rationing as a regime is still grossly inefficient. We study a counterfactual Pigouvian regime that lifts the ration and raises the price of power more than tenfold, to social marginal cost, reflecting both the cost of power and the opportunity cost of water. This regime increases social surplus by INR 11,000 per farmer, for one cropping season, which is $12 \%$ of annual household income in our setting and twice as large as the Government of India's flagship unconditional cash transfer to farmers (Chakraborty, June 01, 2019). The reason for the gain in surplus under Pigouvian reform is not a cut water use, but rather that rationing misallocates water from more to less productive farmers. In a Pigouvian regime, farmers use about the same amount of water as under rationing, on average, but the reallocation of input use raises aggregate productivity in agricultural production by 6 percentage points. This increase in agricultural productivity accounts for most of the increase in social surplus from reform.

The second counterfactual finding is that feasible Pigouvian reforms do not approach a Pareto improvement. We consider several budget-neutral reforms that transfer the revenues from Pigouvian pricing back to farmers uniformly or on the basis of observable factors like land size. We find that at least one quarter of farmers have lower profits net of transfers in these regimes, relative to rationing. The largest losses are for unproductive farmers with relatively large landholdings in areas with deep groundwater, who in an efficient regime would sharply contract. Targeting transfers does not move farmers closer to a Pareto improvement, because much of the heterogeneity in the gains from 
reform is driven by productivity differences that are not observable by the state. Feasible transfer regimes, which condition on observable factors, cannot offset the foregone profits of unproductive large farmers without making smallholders worse off. This finding argues why rationing has been a durable groundwater policy: it is politically difficult to move from rationing to an efficient regime that would harm unproductive farmers whose livelihoods depend on cheap water.

Our paper contributes to the literature in environmental economics on the management of the commons (Ostrom, 1990; Dietz, Ostrom and Stern, 2003). Equity is increasingly seen as an important constraint on environmental policy. Sallee (2019) argues that for many externalities, moving to efficient policies will cause an average increase in surplus that is much smaller than the unobserved heterogeneity in impact across people, making it difficult to achieve a Pareto improvement, as we find here. Donna and Espin-Sanchez (2018) provide an Ostrom-like example of why pricing externalities may be less efficient than local management of the commons. If poor farmers cannot afford to buy water, and all farmers are homogenous in productivity, than a ration or quota system can increase both equity and efficiency. Prior work on groundwater in India has measured the social and economic harm of groundwater shocks for rural households. ${ }^{4}$ There has been wide debate, but less empirical research, on the design of groundwater policy. ${ }^{5}$

Our contribution is to characterize and estimate the efficiency and equity properties of rationing, in a setting where users have heterogenous values for the commons. ${ }^{6}$ The empirical analysis, using agricultural production to recover the value of water, circumvents a basic difficulty in studying rationing: the mechanism under study, in general, prevents us from learning about heterogeneous user demand. Our findings can be viewed as rationalizing the de facto adoption of rationing as India's only groundwater policy: while it entails an efficiency loss, the ration in Rajasthan is set at a roughly efficient level and enacts a large, progressive redistribution of surplus.

\footnotetext{
${ }^{4}$ Sekhri (2014) shows that groundwater depletion increases poverty and sparks civil conflict. Blakeslee, Fishman and Srinivasan (2020) show that farmers whose wells dry up see large declines in farm income and reallocate labor to off-farm work. While the decline in farm income is later nearly offset by gains in off-farm income, households with worse access to water have persistently lower assets and consumption.

${ }^{5}$ Dubash (2007) argues that the present use of groundwater in Indian agriculture is woefully inefficient, and advocates for Ostrom-like steps - the building of trust, local collective action - to lay the political foundation for reform. Shah, Giordano and Mukherji (2012) discuss the origins and politics of the "energy-groundwater nexus" and argue that ideal policies are "politically infeasible." Dubash et al. (2002) studies differences in the community management of water across villages in Gujarat. Fishman et al. (2016) conduct an innovative field trial of payments for water conservation.

${ }^{6} \mathrm{~A}$ related theoretical literature shows how rationing may improve the allocation of essential goods that some people cannot afford to buy, if the benefits of consumption are not too heterogeneous (Weitzman, 1977; Sah, 1987; Wijkander, 1988).
} 
Our findings on the redistribution due to rationing link this study to work in development economics on benefit targeting. Recent research has focused on how to target the explicit benefit transfers in welfare programs (Alatas et al., 2012; Niehaus et al., 2013; Alatas et al., 2016; Hanna and Olken, 2018). We show that rationing entails large transfers, both of an explicit kind, in low power prices, and an implicit kind, due to heterogeneity in the returns to water across farmers with high or low productivity. Rationing the commons thereby redistributes progressively, even along dimensions, like agricultural productivity, that the state cannot observe.

Finally, our study also contributes to the literature at the intersection of development economics and industrial organization on input misallocation. The misallocation of input factors across sectors, firms and farms may lower output and productivity in developing countries (Hsieh and Klenow, 2009; Gollin, Lagakos and Waugh, 2014; Hopenhayn, 2014; Adamopoulos and Restuccia, 2014). A limitation of many studies of misallocation is that they infer misallocation from the residuals of a production model, without any link to a failure of markets or policy, so that the degree of misallocation found depends heavily on model specification (Haltiwanger, Kulick and Syverson, 2018). Gollin and Udry (2019) show that using a richer model, in the context of African agriculture, greatly reduces the estimated degree of misallocation. Our contribution is to relate significant factor misallocation in developing-country agriculture to a specific policy, rationing, which purposefully constrains input use. Our study therefore provides an example of a more direct empirical approach to measure the effects of misallocation on productivity. ${ }^{7}$

The paper proceeds as follows. Section 2 describes the context and data. Section 3 models farmer production under rationing and derives the optimal ration as well as the surplus loss under rationing, relative to a Pigouvian regime. Section 4 presents the empirical strategy and results for our marginal analysis of the ration. Section 5 lays out the structural model, estimates the model and presents counterfactual results. Section 6 concludes.

\footnotetext{
${ }^{7}$ Restuccia and Rogerson (2017) argue that the direct empirical approach of attributing misallocation to specific policies has had limited success up to now: "The essence of the direct approach is to focus on specific sources of misallocation and to assess their consequences. One source of information is quasi-natural experiments that shed light on a particular source of misallocation. While some studies have successfully followed this path, as a practical matter, the scope for this type of assessment seems to be somewhat limited." One example of a prior study that uses the direct approach is Hsieh and Olken (2014), which estimates the effects of labor and tax regulations on the firm size distribution, in several countries, and finds only very small policy-induced distortions.
} 


\section{Context and data}

This section traces the origin of rationing as the de facto regime for groundwater management in India. We then introduce our data sources and use them to describe agriculture in Rajasthan.

\section{a Groundwater and agricultural productivity}

The groundwater crisis in India has its roots in the Green Revolution of the 1960s and 1970s. ${ }^{8}$ Indian policy-makers recognized the importance of inputs complementary to new seed varieties and propelled the Green Revolution by subsidizing fertilizer and groundwater extraction (Shah, Giordano and Mukherji, 2012). Groundwater is extracted using electric pumps set in wells. States therefore set nominal or zero prices for electricity as a subsidy to groundwater use. Over time, the adoption of the high-intensity Green Revolution input bundle has expanded, and more and more farmers have connected pumps to the grid. The resulting rapid growth in groundwater extraction depleted groundwater levels and raised production costs. Accounting for the depletion of this natural capital greatly reduces estimates of productivity growth from the Green Revolution (Murgai, 1999; Murgai, Ali and Byerlee, 2001).

The resulting state of groundwater reserves in India today is dismal. Figure 1, panel A shows the rate of groundwater extraction in India as a fraction of the natural recharge rate of water in each district (Central Groundwater Board, 2013-2014). A large number of Indian districts are classified as having critical levels of extraction or being over-exploited. The map outlines Rajasthan, the state that we study, in black. Rajasthan has an extraordinary concentration of districts with over-exploited groundwater and as a state is extracting groundwater at $137 \%$ of the rate that can naturally be recharged. Independent measures, from satellite data, show that northwestern India, which includes Rajasthan, has the highest rate of groundwater depletion of any large aquifer system in the world (Lo et al., 2016; Rodell, Velicogna and Famiglietti, 2009).

\footnotetext{
${ }^{8}$ The Green Revolution was a world-wide technological advance in agriculture, founded on the development of new high-yielding varieties (HYVs) of staple crops, that brought large increases in output in many developing countries (Gollin, Hansen and Wingender, 2018). While sparked by new seed varieties, the Revolution itself is best described as an intensification of input use, since HYVs are complementary to fertilizer and irrigation. The growth in agricultural output due to the Green Revolution was, for the most part, due to the growth of complementary inputs, rather than new seeds directly raising productivity (Evenson and Gollin, 2003; Kumar and Rosegrant, 1994).
} 


\section{b Electricity rationing to manage the commons}

The de facto regime that has arisen to manage the groundwater commons is rationing. Rationing electricity limits how much water farmers can extract by switching off the electricity grid for most of the day. ${ }^{9}$ Setting a ration does not require charging farmers or even metering consumption, as it is implemented by switching off the power grid at substations upstream, so many states pair rationing with free and unmetered power. Figure 1, panel B shows that rationing has been adopted by many large Indian states, including Gujarat (which had a ration of 8 hours in 2017), Rajasthan (6 hours), Madhya Pradesh (9 hours), Maharashtra (9 hours), Punjab (5 hours), Andhra Pradesh (7 hours), Haryana (9 hours), Karnataka (6 hours) and Tamil Nadu (9 hours). The comparison of panels $\mathrm{A}$ and $\mathrm{B}$ shows that states with higher exploitation of groundwater are more likely to adopt rationing. The states that have adopted rationing have a combined population of 585 million people (365 million in rural areas) and produce $65 \%$ of India's agricultural output. ${ }^{10}$

The politics of rationing are exquisitely sensitive, since in choosing a ration the state is fixing the supply of water, a vital input for farmers. Policy documents provide loose, qualitative guidance on how states need to balance farmers' demand for electricity against the costs to the state (Government of Rajasthan, 2014; Central Electricity Authority, 2018). The press debates the merits of relaxing the ration (Ahuja, May 09, 2018; TNN, Dec 28, 2019). Farmers complain that "my wheat crop suffered in last season due to lack of irrigation." Government officials claim the power ration meets farmers' "requirement" or is "just about sufficient," while citing the enormous fiscal cost of any increase in the ration for the state. The debate on the ration is not as straightforward as this division between farmers and officials would imply. Farmers, who value free power, also realize that rationing, the only check on water extraction, is needed to sustain groundwater levels. In some

\footnotetext{
${ }^{9}$ There are several different ways this is done. Initially, all power to rural areas was cut. Since this practice was obviously painful for domestic users of electricity, who were not extracting water, Gujarat introduced a program to build a second, duplicate electricity distribution system, so that farmers could be rationed separately from other consumers. This method has since been adopted by some other states. In Rajasthan, the ration is imposed by "virtual feeder segregation," in which only a single phase of three-phase alternating current supply is given for most of the day. Three-phase power, which is required to run motors and the appliances that use them, like pumps and compressors, is available for only a limited block of hours. This limits farmer pump use as well as some uses of electricity by domestic consumers.

${ }^{10}$ These numbers are conservative, in that they include only states that explicitly ration power to agricultural users, separately from other rural users of electricity. States that ration all users are likely motivated mainly by the fiscal savings from reduced power supply and not groundwater management (Burgess et al., 2020). If we count states that ration all rural customers, the states that have adopted rationing have a population of 715 million (477 million rural) and account for $71 \%$ of agricultural output.
} 
states, farmers have actively opposed the relaxation of the ration, citing the likelihood of disastrous groundwater depletion (Dayashankar, July 22, 2017; BBC News, September 28, 2017).

\section{c Data sources}

The paper uses two sources of data. First, a new agricultural household survey that we collected. We use this data to measure farmer profits and agricultural practices. Second, data on geological characteristics of the study area that are known to influence groundwater levels.

\section{i Rajasthan farmer survey}

Our main source of data is an original agricultural household survey of farmers in Rajasthan. Our survey instrument was based on the World Bank's Living Standards Measurement Survey - Integrated Surveys on Agriculture (LSMS-ISA), heavily modified to include more detail on irrigation practices, electricity supply and input expenditures. Interviews were conducted from April to August, 2017 with reference to the Rabi 2016-2017 growing season. The Rabi season, which lasts from about November through April, is the dry season of agriculture in Rajasthan (see Appendix A e). There is negligible rainfall during this season, so all cropping is irrigated.

The survey covered farmers in six subdivisions (a unit of utility organization) in four districts of Rajasthan where power is supplied by Jaipur Vidhyut Vitran Nigam Limited (JVVNL). JVVNL is one of three electricity distribution companies in the state, all publicly owned and run. These subdivisions were selected for having a range of groundwater conditions, high numbers of agricultural users of electricity and decent (greater than 65\%) rates of metering for agricultural electricity connections. A sub-division has an average area of $500 \mathrm{~km}^{2}$ and an average population of 170,000 people. The electricity grid serving these subdivisions contains many electricity feeders. A feeder is the $11 \mathrm{kV}$ level of the electricity distribution network and typically serves from fifty to several hundred agricultural consumers. We randomly selected 300 feeders as our primary sampling units. We then randomly sampled 14 farmers from the list of utility customers in each feeder (yielding 4,262 primary respondents in total). We asked farmers about all the crops they grew in the reference season and therefore have production data at the farmer-by-crop level (and, for some inputs, the farmer-crop-plot level). 


\section{ii Geological Data}

We augment our survey data with a spatial dataset of geological characteristicss from "Groundwater Prospect Maps" created by the Bhuvan Bhujal ("earth water") project. The Government of India started the Accelerated Rural Water Supply Programme (ARWSP) to provide clean drinking water to villages across the country. The Bhuvan Bhujal project, a branch of this water supply program, gathered data on geological variables that influence the depth at which groundwater is likely to be available, to identify promising areas in which to dig new wells. The maps are therefore explicitly constructed to measure the determinants of water availability, rather than to measure groundwater levels directly.

We digitized a subset of maps covering the subdivisions in our survey. The main aquifer systems in Rajasthan are in hard rock (phyllite, granite, gneiss and basalt) formations with secondary fractures, meaning that the rock underground is not very porous and water sits on top of rock formations and flows through cracks (Central Groundwater Board, 2013). Hydrogeological research has shown that the type of rock, its porosity, and the density and orientation of these cracks, called lineaments or fractures, are important determinants of local groundwater depth and availability (Sander, 2007; Jasmin and Mallikarjuna, 2011; Mallick et al., 2015; Blakeslee, Fishman and Srinivasan, 2020). We extract variables on rock type, aquifer type and fractures from the Groundwater Prospect Maps, as well as elevation and slope data from topographic sheets (see Appendix A for more detail on these data).

\section{d Rationing in Rajasthan}

Rajasthan has an agricultural share of state product of over 25 percent. Here we describe the power rationing regime in Rajasthan and use our data to show that rationing binds on farmers' input use.

The rationing regime in Rajasthan is typical of the policy across a wide set of states, with low or zero prices and a fixed ration of hours of supply for agricultural users. The agricultural electricity tariff in Rajasthan is Rs 0.9 per kWh (1.5 US cents per kWh, at Rs 60 per USD), against a power purchase cost of Rs 4.75 per kWh (8 US cents) and a distribution cost of Rs 6.20 per kWh (10 US cents). Thus the marginal price of electricity is $15 \%$ of private marginal cost, before even accounting for any value of water. The quantity of electricity supply to agricultural feeders is fixed at six hours 
per day over the whole state. Aside from rationing, there is no explicit groundwater policy: water has no price and property rights over groundwater are not defined.

Figure 2, Panel A shows that the rationing rule is closely followed in our data. More than $80 \%$ of farmers report supply of 6 hours of electricity per day, with the remainder mostly reporting four or five hours. The limited supply of power is binding on power use. Figure 2, Panel B shows farmers' average use of power. The modal usage is 5 hours per day, with the distribution bunched up between four and six hours, against the limit imposed by supply rationing. We consider this distribution to be clear evidence that rationing binds. ${ }^{11}$ It may be objected that water use may not be constrained by the ration, if farmers can add more or larger pumps, to increase the amount of water they extract within the allotted six hours. The state regulates both the number of agricultural pumps and the size of these pumps to prevent such evasion. We provide evidence in Appendix D that these regulations also bind, implying that the supply ration does limit water use.

\section{e Agriculture in the study sample}

Table 1 provides summary statistics at the farmer-level and the farmer-crop level for the variables used in the analysis. Panel A describes farmer-level variables. Farmers grow 2.3 crops on average during the Rabi season (panel A). The average farmer has a total pump capacity of $12.5 \mathrm{hp}$ to lift water from 288 feet underground.

Panel B presents measures of yield, output and farmer profits at the farmer-crop level. Profits, our main outcome, can be hard to measure for agricultural households. We use two measures of profit. First, we directly ask farmers the profit they made on each crop, which we call "cash profits." The coverage of this measure is poor, since, in our sample, most labor is household labor and a large share of output is consumed by farmers themselves. Second, therefore, we compute total profit as the sum of reported profits, when a crop is sold for cash, and imputed profits, when a crop is retained (in whole or part) for own consumption. ${ }^{12}$

Panels C and D describe input quantities and expenditures at the farmer-crop level. Panel C

\footnotetext{
${ }^{11}$ The small gap between hours of supply and use may be accounted for by farmers reporting averages that include days without irrigation or by farmers needing to turn their pumps on when power starts flowing. Some farmers use auto-starters, which switch pumps on automatically, to use every available minute of supply.

${ }^{12}$ The level of imputed profits depends on the wage at which we value household labor input. For our main measure, we value household labor at the market wage, and find mean total profits to be slightly negative (panel D, row 5). Valuing household labor at the lower wage of India's workfare program (MNREGA) yields a positive estimate of mean profits (panel D, rows 6).
} 
shows that the average crop is grown on a plot of 0.65 Ha and uses nearly 1.5 million liters of water for irrigation. The large volume of water used, enough to cover a field of one acre to a depth of 1.2 feet, makes it infeasible for a farmer to pump water in advance in order to relax the ration during the dry season. Mean farmer-crop expenditures on capital and labor (panel D), including the value of own labor, are large, each about INR 17,000 per crop, but expenditure on electricity is small, at INR 1,200. Although water is essential to dry season agriculture, farmers spend practically nothing on water, relative to other inputs, due to electricity subsidies.

The spatial variation in the depth of wells in Rajasthan and, by design, within our study area, is very large. The mean well depth is 288 feet with a standard deviation of 187 feet (Table 1, panel A). The depth to groundwater varies greatly both across and within local areas, which is reflected in the depth of farmer wells. Appendix Figure A1 plots the distributions of well depth by subdivision in our data. Figure 3 maps the variation in farmer well depth for the three areas in our data. ${ }^{13}$ In the area comprising Hindoli and Nainwa subdivisions (Panel B), for example, there are farmers with shallow wells of around one hundred feet to the western part, indicated by the blue end of the color scale. Other farmers, several kilometers east, have wells of three hundred feet or more, indicated by yellow shading. This gap implies that for the same electricity ration the farmers slightly further east would get far less water input than their neighbors.

\section{Model of agricultural production under rationing}

\section{a Environment and the farmer's problem}

Each farmer $i$ has total factor productivity $\Omega_{i}$ and chooses inputs of land $L_{i}$, labor $X_{i}$, capital $K_{i}$ and water $W_{i}$. In the empirical part farmers will grow multiple crops, indexed by $c$, but we omit this subscript for now. Water is extracted with a function

$$
W_{i}\left(H_{i}, D_{i}\right)=\rho \frac{P_{i} H_{i}}{D_{i}}
$$

where $\rho$ is a physical constant, $P_{i}$ is pump capacity, and a farmer runs their pump for $H_{i}$ hours in the day to lift water from depth $D_{i}$ underground. Water extracted is inversely proportional to

\footnotetext{
${ }^{13}$ The data span six sub-divisional offices, but these six SDOs are grouped into three geographic clusters, with each cluster having a range of groundwater conditions.
} 
depth, since the energy it takes to lift water increases linearly in depth (Manring, 2013).

Farmers maximize profits

$$
\begin{aligned}
\Pi_{i}\left(L_{i}, X_{i}, K_{i}, H_{i}\right)= & \max _{X_{i}, K_{i}, H_{i}} \Omega_{i} F\left(L_{i}, X_{i}, K_{i}, W_{i}\left(H_{i}, D_{i}\right)\right)-w_{i} X_{i}-r_{i} K_{i}-p_{E} P_{i} H_{i} \\
& \text { subject to } \quad H_{i} \leq \bar{H} .
\end{aligned}
$$

We treat land $L_{i}$ as exogenous here, since the land market is thin, but empirically will instrument for land cropped. Farmers may face farmer-specific wage and rental rates, to allow for failures in those markets. The production function $F(\cdot, \ldots, \cdot)$ is increasing and concave in its arguments. Electricity is supplied for $\bar{H}$ hours, common across farmers, so farmers must use $H_{i} \leq \bar{H}$ hours, which $\operatorname{cost} p_{E} P_{i} H_{i}$ in electricity bills.

The analysis mainly concerns the allocation of water, so it will be useful to define production and profit functions with water as the only argument, taking land as given and allowing other inputs to endogenously adjust to the use of water. Let

$$
\begin{aligned}
\widetilde{F}_{i}\left(W_{i}\right) & =F\left(L_{i}, X_{i}^{*}\left(W_{i}\right), K_{i}^{*}\left(W_{i}\right), W_{i}\right) \\
X_{i}^{*}\left(W_{i}\right), K_{i}^{*}\left(W_{i}\right) & \in \underset{X_{i}, K_{i}}{\arg \max } \Omega_{i} F\left(L_{i}, X_{i}, K_{i}, W_{i}\right)-w_{i} X_{i}-r_{i} K_{i} \mid W_{i}
\end{aligned}
$$

be production as a function of water. Similarly, let

$$
\widetilde{\Pi}_{i}\left(W_{i}\right)=\Omega_{i} \widetilde{F}_{i}\left(W_{i}\right)-w_{i} X_{i}^{*}-r_{i} K_{i}^{*}
$$

be the profit from the use of water $W_{i}$, omitting the additional cost term $p_{E} P_{i} H_{i}$ that the farmer is charged for the use of his pump. ${ }^{14}$

\section{b The state's problem and the optimal ration}

Consider a narrow version of the state's problem: the state maximizes total surplus, taking as given the low price of electricity $p_{E}$ and the policy regime, a uniform electricity ration.

The state's problem is to choose a ration $\bar{H}$ to maximize social surplus. Suppose the ration

\footnotetext{
${ }^{14}$ Including this term is straightforward and we omit it only to make expressions a little simpler, by keeping the cost of electricity supply in the state's problem and not the farmer's. The direct contribution of electricity costs to farmer profits is small in our setting, since $p_{E}$ is close to zero in Rajasthan (INR 0.90 or 1.5 US cents per kWh).
} 
binds for all farmers, as is nearly the case in the data, and the opportunity cost of water is $\lambda_{W}$ per liter extracted. The state solves

$$
\max _{\bar{H}} \sum_{i}\left[\widetilde{\Pi}_{i}\left(W_{i}\left(\bar{H}, D_{i}\right)\right)-c_{E} P_{i} \bar{H}-\rho \frac{P_{i}}{D_{i}} \bar{H} \lambda_{W}\right] .
$$

The first-order condition for an optimal ration $\bar{H}^{*}$ is

$$
\underbrace{\sum_{i} \frac{d \widetilde{\Pi}_{i}\left(W_{i}\left(\bar{H}^{*}, D_{i}\right)\right)}{d \bar{H}^{*}}}_{\text {Marginal benefit }}=\underbrace{\sum_{i} c_{E} P_{i}+\rho \frac{P_{i}}{D_{i}} \lambda_{W}}_{\text {Marginal social cost }}
$$

The marginal private and social benefits are the same: the additional profits farmers earn when the state increases the ration, allowing farmers to extract more water. The level of the electricity ration controls this vital input, water, and farmers adjust other inputs in response.

The marginal social cost has two parts. The first part is the cost of generating and distributing the additional electricity that farmers use when the ration is increased. The second part is the opportunity cost of water extraction due to the groundwater externality: if a farmer uses water today, the water level will fall, and the cost of water extraction tomorrow will rise, both for that farmer and for others. The cost of the groundwater externality is governed by $\lambda_{W}$, the opportunity cost of water per liter. For the empirical part, we calculate $\lambda_{W}$ directly using a dynamic extension of our model (see Section $4 \mathrm{~d}$ and Appendix E).

The marginal benefit is increasing and concave in water and thus in the ration, inheriting these properties from the production function for each farmer. The marginal social cost is positive and constant; therefore an optimal ration exists. The optimal ration is increasing in farmer productivity $\Omega_{i}$ and the marginal return to water; if farmers profit a lot from water they should be given more. The optimal ration is decreasing in the cost of power and the cost of water extraction, which is the product of the rate of water extraction $\left(\rho P_{i} / D_{i}\right)$ and the opportunity cost of water $\lambda_{W}$. If farmers can lift a lot of water in a short time, then an optimal ration of power will be short. 


\section{c Pigouvian benchmark and efficiency loss from rationing}

The Pigouvian benchmark is to set the prices of all factors equal to their marginal social cost, including opportunity costs. In our setting, the Pigouvian benchmark sets a price of power $p_{E}=c_{E}$ and a price of water $p_{W}=\lambda_{W}$. We maintain throughout that this benchmark is infeasible because water extraction is too costly to monitor. We therefore consider a near-Pigouvian benchmark, which we henceforth call Pigouvian, that prices only power. The farmer-specific Pigouvian price is

$$
p_{E i}^{*}=c_{E}+\rho \frac{1}{D_{i}} \lambda_{W}
$$

The optimal price of electricity is equal to the cost of electricity plus the social cost of the water that a farmer extracts with each unit of electricity consumed. If farmers are homogenous in their extraction technology and depth, though not necessarily in productivity or land, then this price will be homogenous $p_{E i}^{*}=p_{E}^{*}$ and achieve the same allocation as pricing both power and water. If farmers are not homogenous in extraction technology, then the optimal uniform price will balance the marginal benefits and social costs of extraction on average.

The optimal uniform ration will achieve weakly lower surplus than a Pigouvian pricing regime. Suppose, for this argument, that farmers are homogenous in their extraction technology $\rho$, depth $D$, and land, but heterogenous in productivity. Let $\widehat{F}\left(H_{i}\right)=\widetilde{F}\left(W_{i}\left(H_{i}, D\right)\right)$ be production as a function of hours of power use and $p_{H}^{*}$ the Pigouvian price of an hour of use.

Proposition. Let $S^{P}$ be the Pigouvian level of social surplus and $S^{R}$ the level under rationing. The difference in surplus between the Pigouvian and rationing regimes can be written as

$$
S^{P}-S^{R}=\underbrace{\operatorname{Cov}\left(\Omega_{i}, \widehat{F}\left(H_{i}^{*}\right)\right)}_{\text {Input heterogeneity }}+\underbrace{\mathbb{E}\left[\Omega_{i}\right] \mathbb{E}\left[\widehat{F}\left(H_{i}^{*}\right)-\widehat{F}(\bar{H})\right]}_{\text {Mean production gain }}-\underbrace{p_{H}^{*}\left(\mathbb{E}\left[H_{i}^{*}\right]-\bar{H}\right)}_{\text {Resource cost }} .
$$

See Appendix B for the derivation. The gain in social surplus under Pigouvian pricing, relative to a rationing regime, has three terms. The second term is the expected change in the value of output, across all farmers' input choices, when evaluated at the productivity of the mean farmer. The third term is the change in the social cost of water extraction, evaluated at the mean level of extraction. 
Corollary. There exists a ration $\bar{H}$ such that $S^{P}-S^{R}=\operatorname{Cov}\left(\Omega_{i}, \widehat{F}\left(H_{i}^{*}\right)\right)$.

The corollary states that the difference of the second and third terms, the change in social surplus between regimes, evaluated at the average level of farmer productivity, can be set to zero by a well-chosen ration (see Appendix B for the proof). The first term, input heterogeneity, cannot be set to zero with any ration, since no uniform ration will be efficient for all farmers. This term, the covariance between productivity and input use in the Pigouvian allocation, is the allocative loss from forcing heterogeneous farmers to have the same level of power use, and will be greater when productivity is more variable. In this simple example, heterogeneity is due only to differences in productivity, but the same kind of loss will arise due to heterogeneous factor endowments also, for example due to differences in land or in the depth to groundwater across farms.

\section{d Relation of profits to groundwater depth}

The optimal ration, as characterized by equation 2, looks hard to estimate empirically: the key term on the left-hand side, the marginal benefit, is the change in farmer profits with respect to a change in the ration, but the ration does not vary, having been fixed at six hours across the state and for many years. To circumvent this problem, we show here that the marginal benefit of a change in the ration can be estimated, instead, using variation in the depth to groundwater.

The marginal benefit of an increase in the electricity ration $\bar{H}$ is

$$
\begin{aligned}
\sum_{i} \frac{d \widetilde{\Pi}_{i}\left(W_{i}\left(\bar{H}, D_{i}\right)\right)}{d \bar{H}} & =\sum_{i} \frac{d \widetilde{\Pi}_{i}}{d W_{i}} \frac{d W_{i}}{d \bar{H}} \\
& =\sum_{i} \frac{d \widetilde{\Pi}_{i}}{d W_{i}}\left(-\frac{d W_{i}}{d D_{i}} \frac{D_{i}}{H_{i}}\right) \\
& =\sum_{i}-\frac{d \widetilde{\Pi}_{i}}{d D_{i}} \frac{D_{i}}{H_{i}} .
\end{aligned}
$$

The first line assumes that electricity only affects farm profits via water extraction (equation 4). This assumption is accurate in our context; farmers use machines other than irrigation pumps, such as tractors and threshers, but these machines are not powered by electricity. The second line uses the water extraction function (1) to replace the increase in water due to a change in the ration with the increase in water due to a change in depth (5). The idea is that for a given ration a farmer 
would extract more water if the water in their well were a bit shallower, just as they would extract more water if the ration were a bit longer. The last line applies the chain rule.

The derivation shows that depth to groundwater can be used as a stand-in for the electricity ration, to calculate how the ration changes farmer profits. Equation 6 will be the basis of our empirical strategy to estimate the marginal benefit of increasing the ration. While the ration itself does not vary, we do observe variation in the depth to groundwater.

\section{Marginal analysis of the ration}

This section uses a marginal analysis of the response of farmer profits to groundwater depth to measure the marginal benefit of relaxing the ration. We then use our estimate to compare the social marginal benefit and marginal cost of increasing the ration.

\section{a Empirical strategy}

An increase in the ration is socially beneficial to the extent that farmers use it to pump more water and make higher profits. Following equation 6, we estimate how farmer profit depends on the ration from the opposite of the derivative of profit with respect to depth.

The specification is an hedonic, instrumental variables regression to estimate the effect of well depth on farmer profits

$$
\begin{aligned}
\Pi_{i c} & =\beta_{o}+D_{i} \beta_{1}+X_{i c}^{\prime} \beta_{2}+\alpha_{s}+\alpha_{p}+\epsilon_{i c} \\
D_{i} & =\delta_{0}+Z_{i}^{\prime} \delta_{1}+\eta_{i c} .
\end{aligned}
$$

The dependent variable $\Pi_{i c}$ is the total profit of farmer $i$ on crop $c$ per unit of land area. The coefficient of interest is $\beta_{1}=d \Pi / d D$, the estimated effect of well depth on profits, here assumed to be a constant. We use farmer well depth $D_{i}$ as a proxy for groundwater depth. (Appendix A a provides evidence that well depth is a strong proxy with a tight, linear relationship to groundwater depth.) The variables $X_{i c}$ are characteristics of the farmer and crop, such as toposequence (slope and elevation) at the farmer's survey location and the soil characteristics in the farmer's village. We include fixed effects $\alpha_{s}$ for subdivisions and $\alpha_{p}$ for deciles of the plot size distribution, to control 
for land size effects. We discuss the selection of instruments $Z_{i}$ below.

The advantage of using a cross-sectional, Ricardian approach is that it can recover long-run elasticities of profit with respect to water, net of farmer adaptation (Mendelsohn, Nordhaus and Shaw, 1994; Schlenker, Hanemann and Fisher, 2005). We would expect that all inputs have been carefully optimized to the local availability of water (Hornbeck and Keskin, 2014). A potential drawback of such a cross-sectional approach is bias due to endogeneity or omitted variables. On balance, we believe such bias would attenuate ordinary least squares estimates of the effect of depth on profits upwards, towards zero. ${ }^{15}$

We therefore estimate equation 7 using instrumental variables. To provide instruments, we have gathered a rich dataset on the geological determinants of groundwater availability (see Section 2). The main geological characteristics we use as candidate instruments are the type of rock beneath a farmer's location, the length of underground fractures near a farmer, and functions of these variables, such as the type of aquifer system (what geological factors constrain the flow of water in an area). Appendix A describes the underlying geological data and theory. The exclusion restriction is that the geological variables used as instruments do not have a direct effect on farmer profits, other than through their effect on groundwater levels. We view the main threat to excludability as omitted surface characteristics that may be correlated with underground fractures and have a direct effect on productivity. We therefore control for surface characteristics, like elevation, slope, and measures of soil quality, in all our specifications, and consider the robustness of our estimates to varying this set of controls (Appendix C).

We use a machine learning approach to select instruments from a large set of candidate instrumental variables (Belloni et al., 2012). The hydrogeology literature has established that rock and aquifer types and fractures underground change groundwater flow, but the precise way in which they affect groundwater levels and depth is complex. We have a large number of candidate instru-

\footnotetext{
${ }^{15}$ Consider the effect of the several sources of bias separately. First, attenuation bias, since depth is measured with error. If increasing depth lowers profits, as we will find, this would cause us to understate the effect of depth on profits (by estimating a coefficient less negative than the truth). Second, bias may arise due to the endogeneity of depth with respect to farmer productivity. Well depths are determined by how far farmers have to dig to reach groundwater. Groundwater levels, in turn, are a function of the groundwater extraction of farmers. If an area is especially productive, because farmers have a lot of capital or the soil is good, for example, then those farmers would be expected to plant more land and extract more water to irrigate large plots. Greater extraction would then reduce water levels. A naïve regression of profits on depth would then, again, be biased upwards towards zero, since these productive farmers would have lower water levels but still maintain high profits, due to their ex ante higher productivity. Third, as in the hedonic literature on adaptation to climate change, there may be omitted variables bias, which could go in either direction, depending on the correlation of depth with farmer productivity.
} 
ments, including rock types (62 categories), aquifer types (20 categories), the density of fractures around a farmer and interactions of these variables. We therefore allow a large number of candidate instruments and use the post-double selection LASSO approach to select among them in the first stage (Belloni et al., 2012). ${ }^{16}$ Our main set of instruments includes rock type dummies, aquifer types, the density of fractures within 2 kilometers and 5 kilometers of a farmer and the first-order interactions of these variables.

The candidate instrument sets have high predictive power for groundwater depth. Appendix D shows the first stage specifications and measures of fit for various candidate instrument sets. Our preferred specification has a first-stage $F$-statistic of 34 for the selected instruments. The strong predictive power of the instruments can be observed in Figure 3. For example, again considering Hindoli and Nainwa, in panel B, a pocket of farmers to the northwest has shallower wells than their neighbors. The instrument set correctly predicts this local variation, as seen by the lower predicted depths for these farmers in the right side of panel B. The instruments are therefore powerful in aggregate and vary predicted depth at a fine geographic scale.

\section{b Empirical results}

Table 2 presents estimates of the effect of water scarcity on profits (equation 7). In panel A the outcome variable is total profits. In panel B the outcome variable is cash profits. Columns 1 and 2 report results using ordinary least squares and columns 3 and 4 report IV estimates using the LASSO procedure, which we denote as IV-PDS for post-double selection. Column 3 uses the main candidate instrument set and column 4 an alternative, larger instrument set that also includes second-order interactions. Standard errors are clustered at the level of the feeder, the primary sampling unit, to account for spatial correlation.

We find that increases in well depth decrease farmer profits. Our preferred estimates are from the IV-PDS specification in Table 2, panel A, column 3, in which a one standard deviation $(=187$ foot) increase in well depth reduces farmer profits by INR 8.87 thousand per Ha (standard error INR 2.47 thousand per Ha). This estimate is three times larger than the OLS estimate shown in column 2, a difference that supports our conjecture of upward bias in OLS due to attenuation or

\footnotetext{
${ }^{16}$ This approach assumes sparsity, which means that there exists a small subset of variables such that the conditional expectation of the endogeneous variable, given these variables, approximates the conditional expectation given the full set of instruments.
} 
endogeneity. Table 2, panel A, column 4 shows that the effect of depth on profits is similar if we pass a larger set of candidate instruments to LASSO, including second-order interactions.

The magnitude of the effect of groundwater on total profits is economically important. A one standard deviation increase in depth decreases profit by INR 8,900 per Ha in the dry season. This reduction in profit equals 14 percent of output per Ha (Table 1, panel A) or, for an average farmer, $15 \%$ of household income from all sources over the whole year. ${ }^{17}$ A scarcity of groundwater thus significantly harms agricultural livelihoods.

\section{c Robustness checks and mechanisms}

Table 2, Panel B shows estimates of the same specifications using cash profits as the outcome variable. We find large, negative effects of depth on cash profits, with point estimates larger than for total profits. Cash profit is simpler to measure, as it is directly reported by farmers, but we prefer the total profit measure, since it includes the value of own output.

Appendix C studies the robustness of our estimates to specifications with alternative sets of candidate instruments and control variables. The estimated effect of depth on profits is similar to the main estimates, of column 3, if we use instrument sets consisting of only rock type or only aquifer type separately (Appendix D, Table C5, columns 2 and 3). The estimated effect of depth on profits is also robust to keeping the same set of instruments but varying the sets of exogenous control variables, including toposequence, soil quality and plot size effects (Appendix C, Table C6).

The effect of depth on profits is a reduced-form estimate that obscures how farmers adapt their production to water scarcity. To provide some evidence on the mechanisms of farmer adaptation, Appendix D presents additional results for alternative outcome variables. We find that farmers with exogenously deeper wells achieve lower yields and output (Table D8). Farmers adapt to a scarcity of groundwater through disinvestment: they are less likely to use HYV seeds, less likely to use efficient, but capital intensive, irrigation techniques and much more likely to report their crop is under-irrigated (Table D9). We view these findings as showing that water is complementary to other inputs, so that a lack of water causes a broad disinvestment in agriculture. These additional

\footnotetext{
${ }^{17}$ The average farmer plants $2.3 \mathrm{crops}$ in the dry season on land of size $0.65 \mathrm{Ha}$ on average. Therefore, if a farmer's well increased in depth by one standard deviation, his total income would decline by INR $13,000(\approx 8,900 \times 0.65 \times 2.3)$. The mean agricultural household income in rural Rajasthan is INR 88,200 (NSS Agricultural Household Income, Expediture, Assets and Debt Survey).
} 
findings, by illustrating the mechanism of farmer responses to water scarcity, provide further support for our instrumental variables strategy.

\section{d Marginal analysis of the ration}

We now use our estimates to compare the marginal benefits and costs of increasing the ration.

The marginal benefit of increasing the ration follows directly from our estimate of the effect of groundwater depth on profits. Starting from the left-hand side of (2), we use (6) to substitute $d \tilde{\Pi} / d D$ for $d \tilde{\Pi} / d \bar{H}$. We use our preferred estimate of $d \tilde{\Pi} / d D$, a INR 8.87 thousand per Ha decrease in profit per standard deviation of depth (Table 2, Panel A, column 3).

To calculate the marginal cost of increasing the ration we need first to estimate the opportunity cost of water $\lambda_{w}$ (all other parts of the marginal cost of the ration, the right-hand side of equation 2 , are observed). The opportunity cost of water depends on how water extraction today affects groundwater levels tomorrow as well as on the returns to water in agriculture and the discount rate. Appendix E calculates the opportunity cost of water using a simplified, dynamic version of our production model. Our estimates depend on the assumed discount factor as well as our estimates of production function parameters (Section $5 \mathrm{~b}$ ). Our focal estimate of the opportunity cost of water, using a discount factor of $\beta=0.90$, is INR 3.35 per thousand liters, which we use throughout the empirical analysis to measure the opportunity cost of water.

Figure 4 compares the estimated marginal benefit of increasing the ration by one hour to the estimated social marginal cost. The left-hand side axis gives a scale in money units (INR thousand per Ha-hour) and the right-hand axis as a percentage of annual household income. The left-hand bar shows the marginal benefit of increasing the ration by one hour and the three bars at right show the social marginal cost, for discount factors of $\beta=\{0.75,0.90,0.95\}$, respectively. Each of these bars separates social marginal cost into the parts due to the private cost of power (solid base) and to the opportunity cost of water (hollow top part).

Our estimate of the opportunity cost of water implies a large external cost of power use. For a discount factor of $\beta=0.90$, in the fourth bar from the left, the opportunity cost of water is about equal to the cost of the power used to extract it. The social marginal cost of power is therefore nearly twice as large as the private marginal cost, so that the price of power in Rajasthan is a mere $7 \%$ of social marginal cost (INR 0.90 per kWh / INR 12.20 per kWh). 
We find that the estimated marginal benefit of an increase in the ration is greater than the private marginal cost, but somewhat less than the social marginal cost for reasonable discount factors. The marginal benefit of a one hour increase in the ration is a gain in agricultural profit equal to $4 \%$ of household income. This estimated marginal benefit exceeds private marginal cost but is somewhat lower than social marginal cost, at a discount factor of $\beta=0.90$, and meaningfully lower at a discount factor of $\beta=0.95$. Given uncertainty in the estimated marginal benefit, we cannot reject that the marginal benefit of a ration increase is equal to either of private marginal cost or social marginal cost at a discount factor of $\beta=0.90$. The near equality of marginal benefits and social marginal costs implies that the status quo ration is set at a roughly optimal level, or somewhat too high, judging by the point estimates alone. We calculate that a discount factor of $\beta=0.82$ would exactly rationalize the level of the ration as socially efficient, among uniform rations.

This result contradicts the common parable about agricultural groundwater use in India: electricity prices are too low, so farmers must use too much (Kumar and Singh, 2001; Shah, Giordano and Mukherji, 2012; Famiglietti, 2014; Zhang, 2019). If farmers were using too much water, uniformly, then the marginal benefit of additional water should be low. We estimate instead a high marginal benefit to water use. Our finding implies that, despite trivial power prices, the ration keeps farmer pump use in check, on average, at roughly the socially optimal level.

\section{Structural analysis of rationing and counterfactual reforms}

That the ration is about right on average says little about the merits and costs of adopting rationing as a regime, which will hinge on heterogeneity across farmers. This section therefore lays out and estimates a structural model of agricultural production to study how rationing compares to alternative regimes like Pigouvian pricing.

\section{a Empirical model}

We specify a model of agricultural production with multiple inputs where water may be constrained by power rationing. We use a modified version of the Gollin and Udry (2019) approach to estimate the distribution of productivity allowing for measurement error in factor inputs and output. 
The extraction function is fully observed in the data. Farmers extract water with the function (1). Hours $H_{i}$ are endogenous and $\rho$ is a physical constant. We observe pump capacity $P_{i}$ and depth $D_{i}$ in the data and allow farmers to differ on these dimensions.

The production function needs to be estimated. We assume a Cobb-Douglas function, wherein the observed $\log$ total value of output $y_{i c}$ for farmer $i$ from crop $c$ is given by

$$
y_{i c}=\alpha_{L} l_{i c}+\alpha_{X} x_{i c}+\alpha_{K} k_{i c}+\alpha_{W} w_{i c}+\omega_{Y i c}
$$

with log inputs of land $l_{i c}$, labor $x_{i c}$, capital $k_{i c}$ and water $w_{i c}$. Each input $j_{i c}$ is assumed to be observed with classical measurement error in logs, $j_{i c}^{o}=j_{i c}+\epsilon_{J i c}$. The residual $\omega_{Y i c}$ has several parts

$$
\omega_{Y i c}=\underbrace{W_{E i c} \beta_{E}+\omega_{i c}}_{\omega_{E i c}}+\epsilon_{Y i c}
$$

The two components of $\omega_{\text {Eic }}$ are a farmer-specific shock $\omega_{i c}$ and the effect of known output shifters $W_{E i c}$. The farmer observes both components early in the season (hence $E$ ) and makes input choices. The crop is then hit by unobservable shock $\epsilon_{Y i c}$ at harvest, which can represent either a late-season productivity shock or measurement error in output. The econometrician observes $W_{E i c}$ but neither shock. Input choices are endogenous to the $\omega_{i c}$ shock observed by the farmer but not the econometrician.

Substituting realized productivity and observed inputs into the production function, we obtain the estimating equation

$$
\begin{aligned}
y_{i c}= & \alpha_{L} l_{i c}^{o}+\alpha_{X} x_{i c}^{o}+\alpha_{K} k_{i c}^{o}+\alpha_{W} w_{i c}^{o} \\
& -\sum_{J} \alpha_{j i c} \epsilon_{j i c}+W_{E i c} \beta_{E}+\omega_{i c}+\epsilon_{Y i c}
\end{aligned}
$$

We estimate (10) by two-stage least-squares using data at the farmer-by-crop level. We include as controls $W_{E i c}$ a set of SDO fixed effects and variables for elevation, slope and village-level soil quality.

The traditional concern in production function estimation is the endogeneity of input choices to 
productivity (Marschak and Andrews, 1944). Firm-specific variation in factor prices can be used to instrument for input demand (Griliches and Mairesse, 1998). Finding such variation is often difficult for manufacturing firms, but, in an agricultural setting with incomplete markets, the same logic suggests using instruments that affect farmer-specific prices or shadow prices of inputs. We use four sets of variables as instruments, based on (i) geology, (ii) household demographics, (iii) land ownership and (iv) input prices, to estimate the production function. ${ }^{18}$ First stage results are reported in Appendix C, Table C7. The complete instrument set is highly predictive for each of the four endogenous input variables, with first-stage $F$-statistics ranging from 100 to 296 .

To analyze the distributional effects of rationing, we need to estimate not only output elasticities but also farmer productivities. The residuals of (10) will overstate the dispersion in productivity, since they include not only productivity dispersion, but also both measurement error in output and the illusive contribution to output of measurement error in inputs. We therefore follow Gollin and Udry (2019) in deflating the estimated dispersion of productivity to remove the effects of measurement error and cross-farmer differences in input prices or shadow prices. Appendix B describes the approach. The key economic assumption is that farmers face the same shadow prices across all crops they plant. This correction will reduce the dispersion of total factor productivity and is thereby conservative, in the context of our counterfactuals, since it will tend to lessen possible efficiency gains from Pigouvian reform.

\section{b Model estimates}

Table 3 presents estimates of the production function coefficients. Column 1 shows OLS estimates. Column 2 shows instrumental variables estimates treating water as endogenous and all other inputs as exogenous. Column 3 shows instrumental variables estimates treating all four inputs as endogenous. (The first stage results for the column 3 specification are reported in Appendix C,

\footnotetext{
${ }^{18}$ The first set are the geological characteristics that determine groundwater availability, as discussed at length in Section 4 and used in the marginal analysis. The second set are the sizes of land parcels owned, as opposed to cropped. Farmers mainly inherit their land and our survey covered land ownership by parcel as well as land use by crop. We use the size of parcels owned, and functions thereof, which are assumed to be exogenous to productivity, as instruments. This assumption is justified, in rural India, by the state of agricultural land markets. Nearly all agricultural land is inherited and inherited landholdings are sticky, due to a combination of norms, legal barriers and other transaction costs (Fernando, 2020; Awasthi, 2009). The third set is local seed prices, which may affect farmer expenditures on materials, part of capital. The fourth set comprises the number of adult males in the household and the number of adult males squared. When factor markets are incomplete, household demographics may affect labor inputs; see, e.g. LaFave and Thomas (2016), which rejects the completeness of labor markets in Indonesia.
} 
Table C7.) Column 4 takes the column 3 estimates and calibrates the elasticity of output with respect to water, such that the model exactly matches the marginal benefit of relaxing the ration from the marginal analysis (Figure 4, left bar).

The main finding from the production function estimates is that our instrumental variables strategy yields large estimates of the elasticity of output with respect to water, which is a key parameter for calculating the value of reforms to the rationing regime. In the ordinary least squares estimates, output has a positive, precise, but small elasticity with respect to water, of 0.04 (standard error 0.010) (column 1). If we instrument for water input, using only the water-specific geological instruments, by contrast, the water elasticity is far larger, at 0.18 (standard error 0.063 ) (column 2). The large increase in the estimated elasticity of output with respect to water mirrors the difference observed between the OLS and IV specifications for the effect of depth on profits in Table 2. If we instrument for all endogenous inputs, the water coefficient remains large, at 0.15 (standard error 0.060) (column 3).

To compare these estimates against the return to water found in the marginal analysis, we can use the model to calibrate the value of $\hat{\alpha}_{W}$ needed to exactly match our reduced-form estimate, that a one-hour increase in the ration would increase profit by the marginal benefit of Figure 4 . We report the implied $\hat{\alpha}_{W}$ in column 4 . The coefficient of 0.18 (standard error 0.044 ) is very similar to our instrumental variables estimates from columns 2 and 3, showing that the marginal returns to water implied by the reduced-form and structural models are similar. We proceed with the column 4 specification of the production function for our counterfactual analysis. We consider the robustness of our findings to alternate production function specifications with the empirical results.

A second finding from the production function estimates is that production exhibits increasing returns to scale when land is taken as endogenous. The sum of the estimated output elasticities is approximately 1.2, suggesting fairly large increasing returns. In the context of Indian agriculture, increasing returns are plausible, since thin land markets prevent land consolidation, yet many agricultural technologies have fixed costs (Foster and Rosenzweig, 2017). Taking land as exogenous, returns to scale are decreasing for the other three factors together.

Figure 5 shows the estimated dispersion of total factor productivity in the model, both in raw form and after our correction for measurement error. The variance of TFP, after accounting for measurement error, is 0.43 as large as the variance of the raw TFP residual. Correcting the 
productivity residuals for measurement error is therefore important so as not to overstate the dispersion of productivity, and, ultimately, the potential benefits of a Pigouvian reform. The log difference between the 90th and 10th percentiles of the corrected TFP distribution is 0.86 , which is comparable to the productivity dispersion found in African smallholder agriculture. ${ }^{19}$

\section{c Shadow value of the ration}

With the model estimates in hand, we can calculate the heterogenous effects of the status quo ration on farmers. To illustrate how farmer heterogeneity interacts with the rationing regime, we use the model to calculate the shadow cost of the ration for each farmer. The shadow cost of the ration is the price of electricity, in INR per $\mathrm{kWh}$, such that each farmer, if unconstrained, would optimally choose to use the rationed amount of power. Farmers, in our model, are heterogeneous in unobserved productivity, in observed determinants of productivity, and in water extraction per unit of power, due to observable variation in depth to groundwater.

Figure 6 shows the distribution of the shadow cost of the ration, where we have added in the nominal electricity price of INR 0.9 per $\mathrm{kWh}$ to shift the distribution slightly to the right. The mean (median) shadow value of the ration is INR 13 per $\mathrm{kWh}$ (INR 8 per $\mathrm{kWh}$ ), above the private marginal cost of electricity supply, shown in the figure by the vertical dashed line on the left, and very close to the social marginal cost, shown by the line on the right. Clearly, though the price of electricity is low, the ration causes a scarcity of water, and puts a large shadow value on additional electricity use on average.

The shadow cost imposed by the ration shows a remarkable amount of dispersion. The modal shadow cost is less than INR 5 per $\mathrm{kWh}$, and two-thirds of farmers have a shadow cost less than social marginal cost, yet $12 \%$ of farmers, in the right tail, have a shadow cost more than twice social cost. Farmers are likely to have higher shadow costs if they are highly productive, if they have a large endowment of exogenous factors like land, or if they have a good technology for extracting water, such as a large pump in an area with shallow groundwater. In these circumstances, farmers are better able to turn electricity into water and water into profits. The heterogeneity in the model casts the main finding of the marginal analysis (Section 4) in a new light. Even though the six hour ration is roughly efficient, on average, it is set too high for most farmers, and far too low for

\footnotetext{
${ }^{19}$ Gollin and Udry (2019) find values of 0.85 and 1.48 for Uganda and Tanzania, respectively.
} 
a substantial minority. The dispersion in the shadow cost of the ration, which is equivalent to the marginal return to water evaluated at the ration, illustrates the degree of misallocation of water across farmers.

\section{d Counterfactual effects of Pigouvian reform}

\section{i Counterfactual scenarios}

The misallocation of water induced by rationing suggests there may be large efficiency gains from overturning the rationing regime in favor of Pigouvian pricing. This subsection uses the model to study the efficiency and equity effects of such a reform. In all counterfactuals, we take land and labor inputs as fixed rather than endogenous. We think this assumption is appropriately conservative, in a setting where land markets are thin and two-thirds of labor is supplied by households on their own farms.

To consider the effects of reform, we study several counterfactual policy regimes. First, a ration set at the optimal, surplus-maximizing level, rather than the status quo of six hours. Second, a pricing regime that lifts the ration and sets the price of electricity at private marginal cost. Third, a Pigouvian regime that lifts the ration and sets the price of electricity at social marginal cost, including the opportunity cost of water in the price of power. Let $\widetilde{\Pi}_{i}\left(p_{E}\right)$ be the maximized value of profits for farmer $i$ at electricity price $p_{E}$. A Pigouvian regime with a uniform price $p_{E}$ for all farmers is the planner's solution to the problem

$$
p_{E}^{*}=\underset{p_{E}}{\arg \max } \sum_{i} \mathbb{E}\left[\widetilde{\Pi}_{i}\left(p_{E}\right)-c_{E} P_{i} H_{i}\left(p_{E}\right)-\rho_{i} \frac{H_{i}\left(p_{E}\right)}{D_{i}} \lambda_{W}\right] .
$$

In some counterfactual regimes, we allow the state to make transfers to refund the additional revenue from Pigouvian pricing. Any transfer rule the state uses must be based on observable characteristics of consumers. Although there are many farmer characteristics that are theoreti-

cally observable, governments can practically measure only a few, relatively fixed characteristics of farmers, and the policies they adopt must be based on these measures (Scott, 1998). We therefore consider three simple regimes: flat (uniform) transfers across farmers, transfers pro rata on the basis of land size, and transfers pro rata on the basis of pump capacity (see Appendix B b for a formal statement of each rule). Land size and pump capacity are feasible conditions for transfer 
rules, as they are relatively fixed and already tracked by the state.

\section{ii Counterfactual results on efficiency}

Table 4 presents counterfactual results on average surplus, inputs and output at the farmer-crop level. The benchmark regime is the status quo six hour ration (column 1). Column 2 shows the optimal ration, column 3 pricing at private cost, and column 4 Pigouvian pricing. In the column 3 and 4 regimes the ration is lifted, so the only constraint on water use is the 24 hours in a day.

There are three main findings on efficiency from the mean counterfactual outcomes. First, echoing the findings of the marginal analysis, the ration is set at roughly the efficient level, or slightly too high. We calculate an optimal ration of 5 hours (Table 4, panel B, column 2), somewhat less than the 6 hours in the status quo. Farmers use somewhat less power (panel B, row 5, column 2) and produce nearly the same output (panel C, row 1, column 2) as in the status quo.

Second, despite the roughly efficient level at which the status quo ration is set, rationing as a regime has a large efficiency cost, relative to Pigouvian pricing. Under the status quo ration, our estimate of mean surplus is INR 10,000 per farmer-crop (Table 4, panel A, column 1). This total surplus is comprised of farmer-crop profits of INR 20,000, less the unpriced cost of power of INR 5,000 and the opportunity cost of water of INR 5,000; hence profits, measured with subsidies, are cut in half by deducting the private and social costs of water extraction. ${ }^{20}$ Pigouvian pricing increases surplus by roughly INR 4,600 per farmer-crop (Table 4, panel A, column 4 less column 1). We find similar efficiency gains using alternative specifications of the production function. ${ }^{21}$ Under Pigou, farmer profits decline INR 5,700 per farmer-crop, due to higher power prices, but this fall is more than offset by additional revenues to the utility, so that the sum of farmer profit and utility revenue increases (column 4, row 2, where the negative unpriced cost of power is due to Pigouvian prices that exceed the cost of power). Another way of looking at the efficiency loss from rationing, then, is that rationing transfers INR 5,700 in profits to each farmer-crop at the

\footnotetext{
${ }^{20}$ The level of profit calculated in the model is higher than the average level of total profit summarized in Table 1. The difference observed is consistent with the fact that total profits are lower, when reported directly by farmers, than profits calculated from the ground up, using revenues and input costs. In addition, our preferred production function model somewhat overfits the level of output, which increases estimated profits in the model.

${ }^{21}$ We calculate this counterfactual gain under two alternate specifications of the production function to check the robustness of the magnitude of this result. First, the Table 3, column 3 specification. Second, a more flexible specification that allows water to enter production through both $\log W$ and $(\log W)^{2}$ terms. We find surplus gains of INR 4200 to INR 4300 per farmer-crop under these alternate specifications, similar to our main estimate of INR 4600 .
} 
expense of a decline in social surplus of INR 4,600 per farmer-crop, a deadweight loss for each INR 1 transferred of almost INR 0.80 .

The potential gain in surplus from an efficient regime is very large in our context. Farmers grow 2.3 crops per season so an increase in farmer-crop surplus of INR 4,600 works out to a gain in surplus of about INR 11,000 per farmer, for one cropping season. This gain equals $12 \%$ of annual household income or almost twice the value of the Government of India's flagship unconditional cash transfer to farmers (Chakraborty, June 01, 2019).

Third, the surplus gains under a Pigouvian regime are due to increases in productivity, not water conservation. The average water extraction is nearly the same under a Pigouvian regime as under rationing (panel $\mathrm{B}$, row 4, column 4 versus column 1). The difference in surplus in the Pigouvian regime is due to a more efficient use of inputs in both water extraction and agricultural production. Farmers extract nearly the same amount of water in the Pigouvian regime using $20 \%$ less power (panel B, row 5, column 4 versus column 1). Under a pricing regime, farmers with shallower wells, who can get more water per unit power, run their pumps more, increasing water extracted per unit power.

The increase in profit comes mainly from an increase in agricultural productivity. Panel C shows output in each regime (row 1) and the change in output relative to rationing (row 2). We also calculate the gain in output that would have been achieved, relative to status quo rationing, if all farmers saw their inputs change by the same proportional amount (row 3). Gains in agricultural productivity are the residual gain in output not due to average changes in the level of input use (row 4). We find that a Pigouvian regime increases output by $8 \mathrm{pp}$ and that $6 \mathrm{pp}$ of this increase $(75 \%)$ is due to higher productivity. This aggregate productivity increase is the gain in output due only to the reallocation of capital and water inputs across farmers, conditional on the average level of input use.

The counterfactuals therefore show that rationing causes a large reduction in social surplus, equal to $12 \%$ of annual household income. The loss in surplus is due to lower productivity and profits, rather than, as commonly thought, a wasteful overuse of water. 


\section{iii Farmer heterogeneity in response to Pigouvian reform}

The average change in profit masks wide heterogeneity across farmers and crops. Figure 7 shows the average change in profit, before any compensating transfers, due to a reform that replaces rationing with Pigouvian pricing. We plot the average change in profit against land size. There are three lines on the figure: the dashed line shows the mean profits for farmer-crops in the bottom quartile of the productivity distribution, the dashed-and-dotted line for farmer-crops in the top quartile, and the solid line for all farmers.

Nearly all farmers lose from reform, before transfers, since electricity prices are more than tenfold higher; the solid line showing the change in profit for all farmers is below zero almost everywhere. The average change in profit shows a skewed, U-shaped relationship with land size: it is decreasing in land size at low levels of land, but increasing above about the 80th percentile of the land size distribution, turning positive around the 95th percentile. For the largest farmers, reform makes average profits go up, despite the increase in prices.

This U-shaped relationship between the gain from reform and land size is due to a subtle underlying heterogeneity in the response to reform for farmers of differing productivity. The expected loss or gain for a farmer-crop depends on the interactions of observable factors like land size with productivity. The dashed line in Figure 7 shows the average change in profit for unproductive farmers. For unproductive farmers, the larger their landholding, the more they lose from reform. When the Pigouvian regime raises prices, unproductive farmers contract production sharply; their loss from reform is therefore well approximated by their profit ex ante in the rationing regime, which is increasing in land size. The relationship between land and the gains from reform is starkly different for productive farmers, as shown by the dashed-and-dotted line. For low levels of landholding, productive farmers lose more than unproductive farmers; because they are more productive, it is optimal for these farmers to keep using higher amounts of water after the reform, despite that water is newly costly. At high levels of landholding, however, productive farmers gain from reform, even before transfers. The reason is that productive farmers with large landholdings are likely to have been heavily constrained under the rationing regime (Figure 6). A farmer that faced a high shadow cost of the ration, if sufficiently large and productive, may profit enough from the lifting of the ration to more than offset the roughly tenfold increase in electricity prices. 
This heterogeneity poses a difficulty for the state in setting compensatory transfers: observed farmer characteristics may be a poor guide to the magnitude, and even the sign, of gains from Pigouvian reform. A large landholder may require compensation of INR 10 thousand per season, if he is unproductive, or see a leap in profit of INR 30 thousand per season, if she is highly productive. The state cannot, moreover, infer these differences in productivity from ex ante consumption, since all farmers appear to have the same demand when the ration binds (Figure 2, Panel B).

\section{iv Counterfactual results on redistribution}

The combination of large average gains in surplus and heterogeneity in the impacts of reform creates a tension: the state, under a Pigouvian reform, has a large budget to distribute, but finds it hard to target that budget well enough to achieve a Pareto improvement (Sallee, 2019).

Table 5 studies the distributional impacts of Pigouvian reform. Column 1 again describes the status quo rationing regime and columns 2 through 5 all describe Pigouvian regimes, which differ only in the transfer rule: no transfers (column 2), flat or uniform transfers (column 3), transfers pro rata on pump capacity (column 4), and transfers pro rata on land size (column 5). Panel A shows statistics on the level and variation in profits, transfers, and profits net of transfers under each regime. Panel $\mathrm{B}$ shows statistics on the change in profits from the status quo to each respective Pigouvian regime and the characteristics of farmers who see increases or decreases in profit under each regime. All statistics in the table are aggregated across crops to the farmer level.

The transfer budget in a Pigouvian regime is substantial - about INR 22,000 per farmer (Table 5, panel A, column 3). This budget equals one quarter of annual household income and is nearly four times as large as the Government of India's flagship unconditional cash transfer to farmers (Chakraborty, June 01, 2019). The choice of rationing as a policy regime thus commits the government to spend far more in power and water subsidies than it spends on an explicit cash transfer program for the same target population.

Without any transfers, Pigouvian reform is highly regressive, as it benefits only large and profitable farmers who are constrained by the ration. Before transfers, only $10 \%$ of farmers increase their profits under the Pigouvian regime (panel B, column 2). These farmers who gain have $4 \times$ higher ex ante profits, $3 \times$ higher landholdings, higher productivity and shallower wells, relative to farmers for whom Pigouvian reform decreases profits (panel B, column 2, top half versus bottom 
half). The intuition for these stark differences carries forward from our discussions of Figure 6 and Figure 7; productive, large farmers are more likely to have a high shadow cost of the ration and therefore to gain from the ration being lifted, even if the price of electricity is increased at the same time.

The main finding of Table 5 is that the state is unable to use Pigouvian reform to enact a Pareto improvement, even net of large compensating transfers. After a flat transfer to farmers, $74 \%$ of farmers would prefer a Pigouvian regime to rationing, while $26 \%$ would see net profits decline (panel B, column 2). The transfer therefore offsets losses for a large majority of farmers, though far from all. Flat transfers reverse the pattern of who gains and who loses from reform, by overcompensating small and unprofitable farmers. Net of flat transfers, the remaining losers tend to be farmers with high ex ante profits, land, and productivity and deeper wells, who benefit greatly from the subsidy in lifting water to the surface (panel B, column 3, bottom part). Removing rationing would therefore, in the regime with flat transfers, most harm productive, moderate landholders in areas with severe groundwater depletion.

Targeting these transfers would actually increase the number of farmers who lose from Pigouvian reform. Targeting would appear to be a promising way to offset the concentrated losses of large, unproductive farmers (Figure 7). We find, however, that targeting transfers on pump capacity or land size increases the share of farmers who are worse off under Pigou from $26 \%$, under flat transfers (panel B, column 3), to $32 \%$ under pump-based transfers or $39 \%$ under land-based transfers (columns 4 and 5, respectively). Consider the land-based transfer regime of column 5. The state, by conditioning transfers on landholdings, spends a large part of its budget on large farmers who may have profited even without transfers, leaving a smaller budget for unproductive smallholders. The share of losers goes up because less productive smallholders are numerous and their profits net of transfers decline (panel B, column 5). Targeting mainly shifts the burden of losses. Under land-based targeting, farmers who lose had mean profits under rationing $32 \%$ smaller than those who lose under flat transfers, as well as somewhat lower landholdings (panel B, column 5 versus column 2). Targeting therefore reduces the degree of loss, for profitable but unproductive farmers, at the expense of spreading losses across a wider group.

We interpret these results as an instance of the difficulty of using Pigouvian reform to reach a Pareto improvement when users of the commons are unobservably heterogeneous. The direct 
effect of Pigouvian reform is regressive, since lifting the ration benefits most the farmers who are productive and have ample land and shallow groundwater. The aggregate surplus gains, and therefore transfer budget, in our setting, are very large compared to the value added in agriculture. Yet the state cannot target on productivity, a key determinant of the gains from reform, and therefore, under plausible transfer regimes, leaves a large number of farmers worse off.

\section{Conclusion}

This paper has studied the efficiency and equity consequences of India's de facto policy regime for managing groundwater, rationing the commons.

We have three main findings. First, the ration is set at a roughly efficient level and can be rationalized by reasonable discount factors. This statement of efficiency is based on contemporaneous estimates of the return to water and a forward-looking opportunity cost of water, and does not imply that past groundwater use, much of which preceded the rationing regime, has been socially efficient. Second, notwithstanding that the ration is set efficiently, rationing as a regime is inefficient, causing a loss in social surplus equal to $12 \%$ of annual household income. Against common wisdom, the source of this inefficiency is not that farmers are using too much water, but rather that the wrong farmers are using it, from the narrow point of view of economic efficiency. Third, despite the inefficiency of rationing, feasible Pigouvian reforms do not approach a Pareto improvement.

While rationing is inefficient, it has arguably endured because it guarantees equity in access to groundwater, which is vital for small farmers and has enabled much of India's agricultural productivity gains in the last fifty years. Rationing may increase social welfare, even as it decreases social surplus, because it transfers surplus from large, productive farmers in areas with shallow water to small, unproductive farmers with deep water. Remarkably, rationing enacts these transfers, towards unproductive farmers, without any money changing hands and without the state needing to observe productivity. The cost of these transfers is fairly high; by our estimates, there is a deadweight loss of almost INR 1 of social surplus for each INR 1 transferred. Nonetheless, explicit transfer programs, in India and other developing countries, sometimes have rates of leakage that are even higher (Niehaus and Sukhtankar, 2013; Olken and Pande, 2012). The merits of rationing 
as a transfer regime therefore depend on the alternative. We expect that improvements in the delivery of benefit transfers will make rationing look relatively worse, by comparison, over time (Muralidharan, Niehaus and Sukhtankar, 2016).

For most large scale commons problems, the expert consensus on efficient policies is overwhelming, yet it remains that these policies are seldom adopted. The kind of distributional analysis we have undertaken, which links misallocation to specific policies and studies the efficiency and equity consequences of these policies together, is one way to understand why regimes that are inefficient may still be widespread and durable.

\section{References}

Adamopoulos, Tasso, and Diego Restuccia. 2014. "The size distribution of farms and international productivity differences." American Economic Review, 104(6): 1667-97.

Ahuja, Mohan. May 09, 2018. "Farmers get 5-7 hours power daily, second lowest in India." Hindustan Times.

Alatas, Vivi, Abhijit Banerjee, Rema Hanna, Benjamin A Olken, and Julia Tobias. 2012. "Targeting the poor: evidence from a field experiment in Indonesia." American Economic Review, 102(4): 1206-40.

Alatas, Vivi, Ririn Purnamasari, Matthew Wai-Poi, Abhijit Banerjee, Benjamin A Olken, and Rema Hanna. 2016. "Self-targeting: Evidence from a field experiment in Indonesia." Journal of Political Economy, 124(2): 371-427.

Awasthi, Maya Kant. 2009. "Dynamics and resource use efficiency of agricultural land sales and rental market in India." Land Use Policy, 26(3): 736 - 743.

Baird, Ian G. 2010. Quotas, Powers, Patronage and Illegal Rent-Seeking: The Political Economy of Logging and the Timber Trade in Southern Laos. Forest Trends.

BBC News. September 28, 2017. "India farmers say no to 24-hour power." BBC Telugu.

Belloni, Alexandre, Daniel Chen, Victor Chernozhukov, and Christian Hansen. 2012. "Sparse models and methods for optimal instruments with an application to eminent domain." Econometrica, 80(6): 2369-2429.

Blakeslee, David, Ram Fishman, and Veena Srinivasan. 2020. "Way down in the hole: adaptation to long-term water loss in rural India." American Economic Review, 110(1): 200-224.

Burgess, Robin, Matthew Hansen, Benjamin A. Olken, Peter Potapov, and Stefanie Sieber. 2012. "The Political Economy of Deforestation in the Tropics*." The Quarterly Journal of Economics, 127(4): 1707-1754.

Burgess, Robin, Michael Greenstone, Nicholas Ryan, and Anant Sudarshan. 2020. "The Consequences of Treating Electricity as a Right." Journal of Economic Perspectives, 34(1): 14569. 
Central Electricity Authority. 2018. "National Electricity Plan." Central Electricity Authority, Government of India, Ministry of Power.

Central Groundwater Board. 2013. "District Reports." Central Groundwater Board, Government of India, Ministry of Power.

Central Groundwater Board. 2013-2014. "Annual Report." Central Groundwater Board, Government of India, Ministry of Power.

Central Groundwater Board. 2015-16. "Annual Report." Central Groundwater Board, Government of India, Ministry of Power.

Chakraborty, Debjit. June 01, 2019. "Modi Increases Cash Transfer for Farmers to $\$ 12.5$ billion." Bloomberg.

Coase, Ronald H. 1960. "The problem of social cost." Journal of Law and Economics, 1: 63.

Daily, Gretchen C, Tore Söderqvist, Sara Aniyar, Kenneth Arrow, Partha Dasgupta, Paul R Ehrlich, Carl Folke, AnnMari Jansson, Bengt-Owe Jansson, Nils Kautsky, et al. 2000. "The value of nature and the nature of value." Science, 289(5478): 395-396.

Davis, Lucas W. 2008. "The effect of driving restrictions on air quality in Mexico City." Journal of Political Economy, 116(1): 38-81.

Davis, Lucas W, and Lutz Kilian. 2011. "The allocative cost of price ceilings in the US residential market for natural gas." Journal of Political Economy, 119(2): 212-241.

Dayashankar, K M. July 22, 2017. "Farmers say no to 24 x 7 power supply." The Hindu.

Dietz, Thomas, Elinor Ostrom, and Paul C Stern. 2003. "The struggle to govern the commons." Science, 302(5652): 1907-1912.

Donna, Javier D., and Jose-Antonio Espin-Sanchez. 2018. "The Illiquidity of Water Markets: Efficient Institutions for Water Allocation in Southeastern Spain." Mimeo, Yale University.

Dubash, Navroz K. 2007. "The electricity-groundwater conundrum: Case for a political solution to a political problem." Economic and Political Weekly, 45-55.

Dubash, Navroz K, et al. 2002. Tubewell capitalism: groundwater development and agrarian change in Gujarat. Oxford University Press.

Evenson, Robert E, and Douglas Gollin. 2003. "Assessing the impact of the Green Revolution, 1960 to 2000." Science, 300(5620): 758-762.

Famiglietti, James S. 2014. "The global groundwater crisis." Nature Climate Change, 4(11): 945.

Fernando, A Nilesh. 2020. "Shackled to the Soil? Inherited Land, Birth Order, and Labor Mobility." Journal of Human Resources, 0219-10014R2.

Fishman, Ram, Upmanu Lall, Vijay Modi, and Nikunj Parekh. 2016. "Can Electricity Pricing Save India's Groundwater? Field Evidence from a Novel Policy Mechanism in Gujarat." Journal of the Association of Environmental and Resource Economists, 3(4): 819-855. 
Foster, Andrew D, and Mark R Rosenzweig. 2017. "Are There Too Many Farms in the World? Labor-Market Transaction Costs, Machine Capacities and Optimal Farm Size." National Bureau of Economic Research Working Paper 23909.

Frech III, HE, and William C Lee. 1987. "The welfare cost of rationing-by-queuing across markets: Theory and estimates from the US gasoline crises." The Quarterly Journal of Economics, 102(1): 97-108.

Gardner, R, M.R. Moore, and J.M. Walker. 1997. "Governing a groundwater commons: A strategic and laboratory analysis of Western water law." Economic Inquiry, 35: 218-234.

Gollin, Douglas, and Christopher Udry. 2019. "Heterogeneity, Measurement and Misallocation in African Agriculture." National Bureau of Economic Research working paper 25440.

Gollin, Douglas, Casper Worm Hansen, and Asger Wingender. 2018. "Two Blades of Grass: The Impact of the Green Revolution." National Bureau of Economic Research Working Paper 24744.

Gollin, Douglas, David Lagakos, and Michael E Waugh. 2014. "The agricultural productivity gap." The Quarterly Journal of Economics, 129(2): 939-993.

Government of Rajasthan. 2014. "24x7-Power For All." Government of Rajasthan, Government of Rajasthan and Government of India.

Griliches, Zvi, and Jacques Mairesse. 1998. "Production Functions: The Search for Identification." In Econometrics and Economic Theory in the Twentieth Century: The Ragnar Frisch Centennial Symposium., ed. S Strom. Cambridge University Press.

Haltiwanger, John, Robert Kulick, and Chad Syverson. 2018. "Misallocation measures: The distortion that ate the residual." National Bureau of Economic Research 24199.

Hanna, Rema, and Benjamin A Olken. 2018. "Universal basic incomes versus targeted transfers: Anti-poverty programs in developing countries." Journal of Economic Perspectives, 32(4): 201-26.

Hopenhayn, Hugo A. 2014. "Firms, misallocation, and aggregate productivity: A review." Annual Review of Economics, 6(1): 735-770.

Hornbeck, Richard, and Pinar Keskin. 2014. "The historically evolving impact of the ogallala aquifer: Agricultural adaptation to groundwater and drought." American Economic Journal: Applied Economics, 6(1): 190-219.

Hsieh, Chang-Tai, and Benjamin A Olken. 2014. "The missing "missing middle"." Journal of Economic Perspectives, 28(3): 89-108.

Hsieh, Chang-Tai, and Peter J Klenow. 2009. "Misallocation and manufacturing TFP in China and India." The Quarterly journal of economics, 124(4): 1403-1448.

Jackson, Matthew O. 2018. "The Political Challenges of Large Commons Problems." Mimeo, Stanford Univeristy.

Jasmin, Ismail, and P Mallikarjuna. 2011. "Satellite-based remote sensing and geographic information systems and their application in the assessment of groundwater potential, with particular reference to India." Hydrogeology Journal, 19(4): 729-740. 
Kumar, M Dinesh, and OP Singh. 2001. "Market instruments for demand management in the face of scarcity and overuse of water in Gujarat, Western India." Water Policy, 3(5): 387-403.

Kumar, Praduman, and Mark W Rosegrant. 1994. "Productivity and sources of growth for rice in India." Economic and Political Weekly, A183-A188.

LaFave, Daniel, and Duncan Thomas. 2016. "Farms, families, and markets: New evidence on completeness of markets in agricultural settings." Econometrica, 84(5): 1917-1960.

Lee, S, I Park, and JK Choi. 2012. "Spatial Prediction of Ground Subsidence Susceptibility Using An Artificial Neural Network." Environmental Management, 347-358.

Libecap, Gary D. 2011. "Institutional Path Dependence in Climate Adaptation: Coman's "Some Unsettled Problems of Irrigation"." American Economic Review, 101(1): 64-80.

Li, Shanjun. 2017. "Better Lucky Than Rich? Welfare Analysis of Automobile Licence Allocations in Beijing and Shanghai." The Review of Economic Studies, 85(4): 2389-2428.

Lockhart, Richard, Jonathan Taylor, Ryan J Tibshirani, and Robert Tibshirani. 2014. "A significance test for the lasso." Annals of statistics, 42(2): 413.

Lo, Min-hui, James S. Famiglietti, John T. Reager, Matthew Rodell, Sean Swenson, and Wen-Ying Wu. 2016. "Terrestrial Water Cycle and Climate Change: Natural and HumanInduced Impacts." , ed. Qiuhong Tang and Taikan Oki, Chapter GRACE-Based Estimates of Global Groundwater Depletion. John Wiley \& Sons.

Lund, Jay R., and Robert U. Reed. 1995. "Drought Water Rationing and Transferable Rations." Journal of Water Resources Planning and Management, 121(6): 429-437.

Mallick, Javed, Chander Kumar Singh, Hussein Al-Wadi, Mohd Ahmed, Atiqur Rahman, Satyanarayan Shashtri, and Saumitra Mukherjee. 2015. "Geospatial and geostatistical approach for groundwater potential zone delineation." Hydrological Processes, 29(3): 395-418.

Manring, Noah D. 2013. Fluid Power Pumps and Motors: Analysis, Design, and Control. McGraw-Hill Education.

Mansur, Erin T, and Sheila M Olmstead. 2012. "The value of scarce water: Measuring the inefficiency of municipal regulations." Journal of Urban Economics, 71(3): 332-346.

Marschak, Jacob, and William H Andrews. 1944. "Random simultaneous equations and the theory of production." Econometrica, Journal of the Econometric Society, 143-205.

Maxwell, James A, and Margaret N Balcom. 1946. "Gasoline Rationing in the United States, I." The Quarterly Journal of Economics, 60(4): 561-587.

Mendelsohn, Robert, William D Nordhaus, and Daigee Shaw. 1994. "The impact of global warming on agriculture: a Ricardian analysis." American Economic Review, 753-771.

Muralidharan, Karthik, Paul Niehaus, and Sandip Sukhtankar. 2016. "Building state capacity: Evidence from biometric smartcards in India." American Economic Review, 106(10): 2895-2929.

Murgai, Rinku. 1999. The Green Revolution and the productivity paradox: evidence from the Indian Punjab. The World Bank. 
Murgai, Rinku, Mubarik Ali, and Derek Byerlee. 2001. "Productivity growth and sustainability in post-Green Revolution agriculture: the case of the Indian and Pakistan Punjabs." The World Bank Research Observer, 16(2): 199-218.

National Ground Water Association. 2016. "Facts About Global Groundwater Usage." National Ground Water Association, http://www.ngwa.org/Fundamentals/Documents/globalgroundwater-use-fact-sheet.pdf.

Newell, Richard G, William A Pizer, and Daniel Raimi. 2014. "Carbon market lessons and global policy outlook." Science, 343(6177): 1316-1317.

Niehaus, Paul, and Sandip Sukhtankar. 2013. "The marginal rate of corruption in public programs: Evidence from India." Journal of Public Economics, 104: 52-64.

Niehaus, Paul, Antonia Atanassova, Marianne Bertrand, and Sendhil Mullainathan. 2013. "Targeting with agents." American Economic Journal: Economic Policy, 5(1): 206-38.

Ohler, Adrienne, Hayley Chouinard, and Jonathan Yoder. 2007. "Welfare Trade-offs between Transferable and Non-Transferable Lotteries." Western Agricultural Economics Association 2007 Annual Meeting, July 29-August 1, 2007, Portland, Oregon 7363.

Olken, Benjamin A, and Rohini Pande. 2012. "Corruption in developing countries." Annu. Rev. Econ., 4(1): 479-509.

Olmstead, Alan L, and Paul Rhode. 1985. "Rationing without government: The west coast gas famine of 1920." American Economic Review, 75(5): 1044-1055.

Ostrom, Elinor. 1990. Governing the Commons: The Evolution of Institutions for Collective Action. Cambridge University Press.

Ostrom, Elinor. 1991. Crafting institutions for self-governing irrigation systems. Institute for Contemporary Studies, San Francisco, CA, US.

Ostrom, Elinor. 2009. "A general framework for analyzing sustainability of social-ecological systems." Science, 325(5939): 419-422.

Ostrom, Elinor, and Roy Gardner. 1993. "Coping with Asymmetries in the Commons: SelfGoverning Irrigation Systems Can Work." Journal of Economic Perspectives, 7(4): 93-112.

Oxford University Press. 2011. "India Infrastructure Report." Oxford University Press, Oxford University Press.

Pigou, Arthur. 1932. The Economics of Welfare. Routledge.

Restuccia, Diego, and Richard Rogerson. 2017. "The causes and costs of misallocation." Journal of Economic Perspectives, 31(3): 151-74.

Rodell, Matthew, Isabella Velicogna, and James S Famiglietti. 2009. "Satellite-based estimates of groundwater depletion in India." Nature, 460(7258): 999.

Sah, Raaj Kumar. 1987. "Queues, rations, and market: comparisons of outcomes for the poor and the rich." American Economic Review, 69-77. 
Sallee, James M. 2019. "Pigou Creates Losers: On the Implausibility of Achieving Pareto Improvements from Efficiency-Enhancing Policies." National Bureau of Economic Research 25831.

Sander, Per. 2007. "Lineaments in groundwater exploration: a review of applications and limitations." Hydrogeology Journal, 15(1): 71-74.

Schlenker, Wolfram, W Michael Hanemann, and Anthony C Fisher. 2005. "Will US agriculture really benefit from global warming? Accounting for irrigation in the hedonic approach." American Economic Review, 95(1): 395-406.

Scott, James C. 1998. Seeing like a state: How certain schemes to improve the human condition have failed. Yale University Press.

Scrogin, David, Robert P Berrens, and Alok K Bohara. 2000. "Policy changes and the demand for lottery-rationed big game hunting licenses." Journal of Agricultural and Resource Economics, 501-519.

Sekhri, Sheetal. 2014. "Wells, water, and welfare: the impact of access to groundwater on rural poverty and conflict." American Economic Journal: Applied Economics, 6(3): 76-102.

Shah, Tushaar, Mark Giordano, and Aditi Mukherji. 2012. "Political economy of the energygroundwater nexus in India: exploring issues and assessing policy options." Hydrogeology Journal, 20(5): 995-1006.

Shakti Foundation. 2016. "Case Studies of DSM Projects Implemented in India." Shakti Foundation, Shakti Foundation.

Stankey, George H. 1979. "Use rationing in two southern California wildernesses." Journal of Forestry, 77(6): 347-349.

Timmins, Christopher. 2002. "Measuring the dynamic efficiency costs of regulators' preferences: Municipal water utilities in the arid west." Econometrica, 70(2): 603-629.

TNN. Dec 28, 2019. "Punjab may withdraw power subsidy to 'large' farmers."

Viard, V Brian, and Shihe Fu. 2015. "The effect of Beijing's driving restrictions on pollution and economic activity." Journal of Public Economics, 125: 98-115.

Walker, Brian, Scott Barrett, Stephen Polasky, Victor Galaz, Carl Folke, Gustav Engström, Frank Ackerman, Ken Arrow, Stephen Carpenter, Kanchan Chopra, et al. 2009. "Looming global-scale failures and missing institutions." Science, 325(5946): 1345-1346.

Weitzman, Martin L. 1977. "Is the price system or rationing more effective in getting a commodity to those who need it most?" The Bell Journal of Economics, 517-524.

Wijkander, Hans. 1988. "Equity and efficiency in public sector pricing: A case for stochastic rationing." Econometrica: Journal of the Econometric Society, 1455-1465.

Zhang, Fan. 2019. "In the Dark: How Much Do Power Sector Distortions Cost South Asia?" South Asia Development Forum. Washington, DC: World Bank. 


\section{$7 \quad$ Figures}

Figure 1: Groundwater Depletion in India

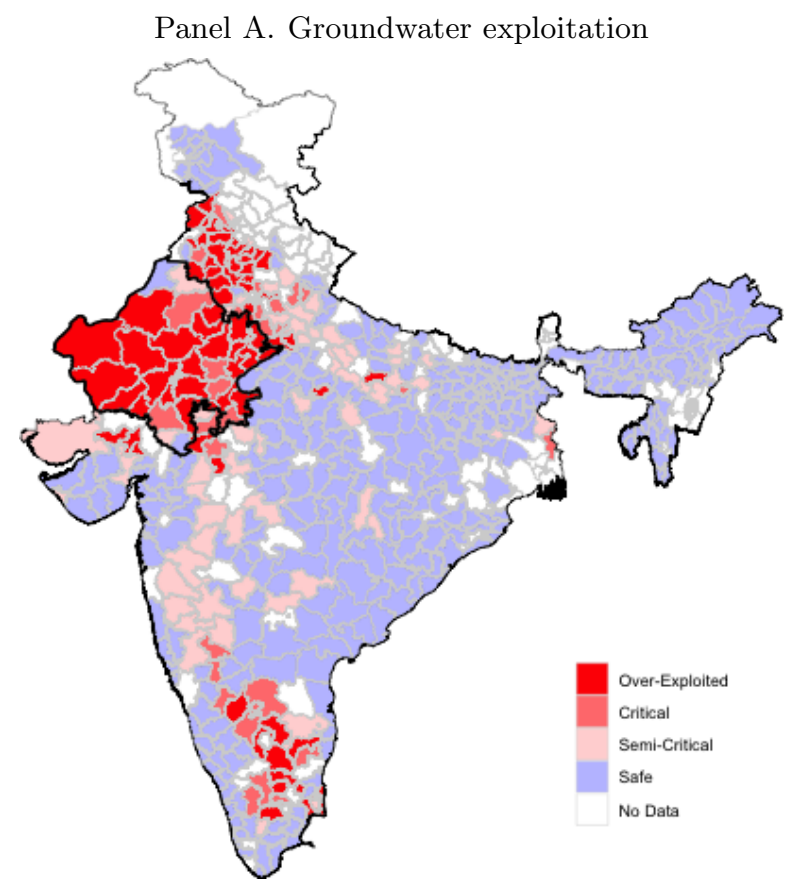

Panel B. States that ration power for agricultural use

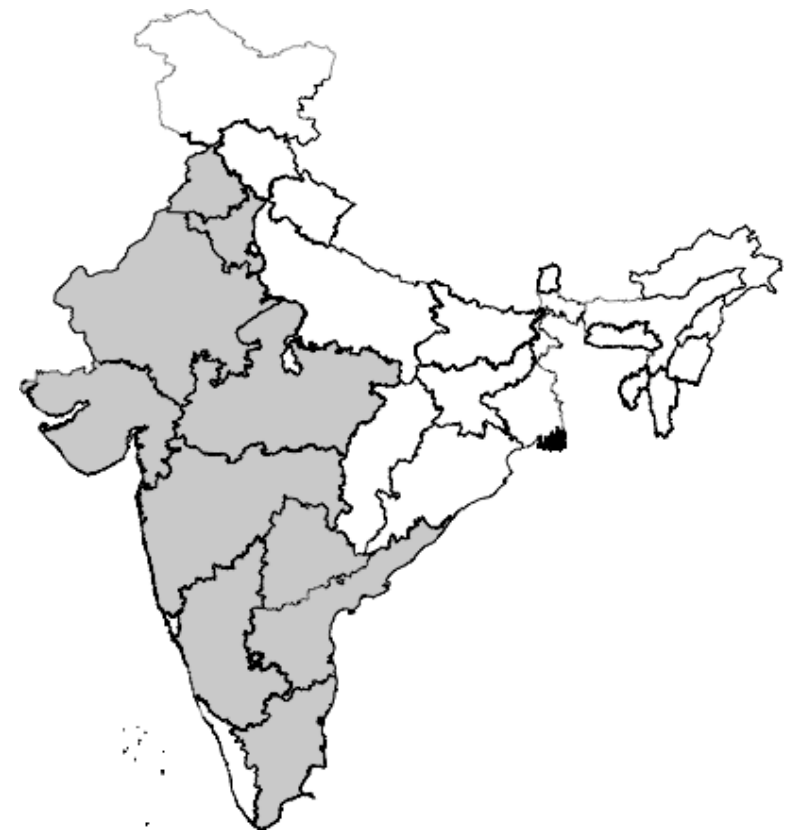

The figure shows the exploitation of groundwater in India. Panel A shows the classification of the rates of groundwater extraction by district (Central Groundwater Board, 2015-16). The color code indicates the degree to which the rate of groundwater extraction exceeds the natural rate of groundwater recharge due to rainfall. The classifications are determined by the Central Groundwater Board: safe is extraction from 0 to $70 \%$ of recharge, semi-critical from $70-90 \%$, critical from $90-100 \%$, and over-exploited above $100 \%$. The boundary of the state of Rajasthan, in the northwest, which contains our study area, is shown by the heavy black border. Panel B shades in gray the states in India that have adopted a rationing regime for power supply to farmers. 
Figure 2: Rationing of Power Supply in Rajasthan

Panel A. Hours of Supply

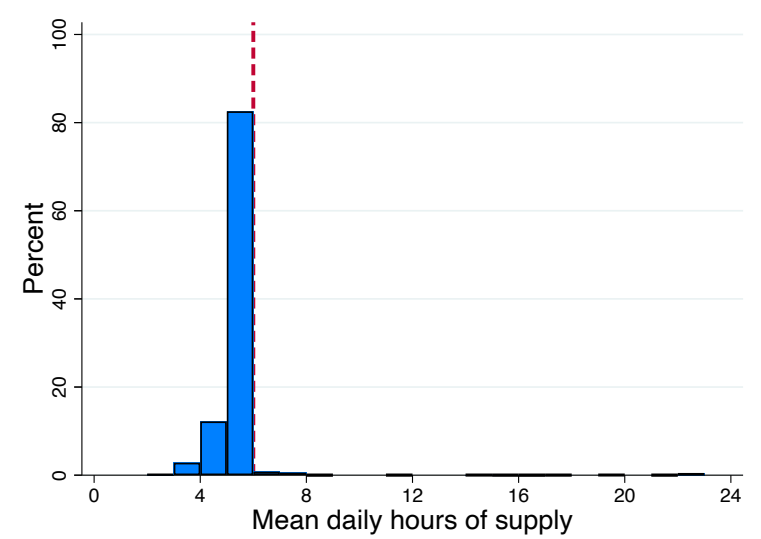

Panel B. Hours of Use

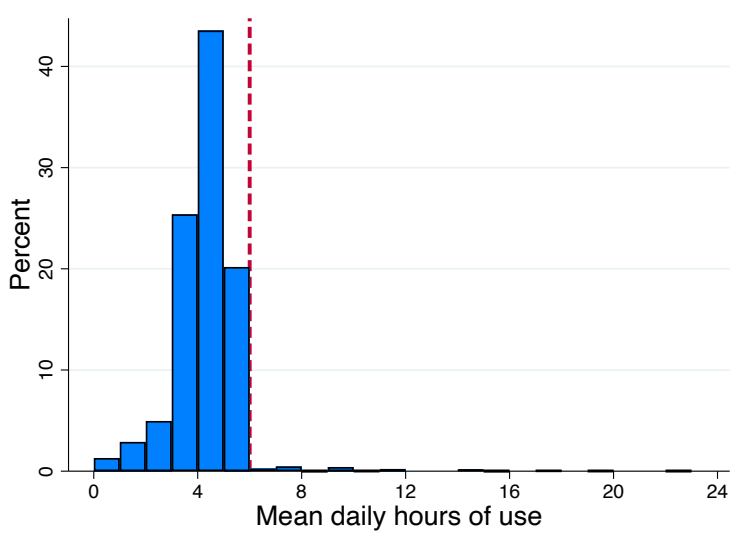

The figure shows power rationing using data from our agricultural survey in Rajasthan. Panel A shows the distribution of the average hours of supply per day during the Rabi season of 2016-2017. Panel B shows the distribution of the average hours of use over the season. 
Figure 3: Variation in Well Depth

True Depths

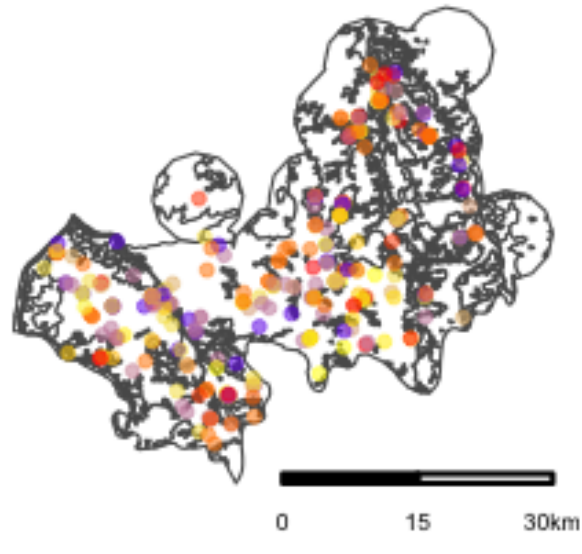

True Depths

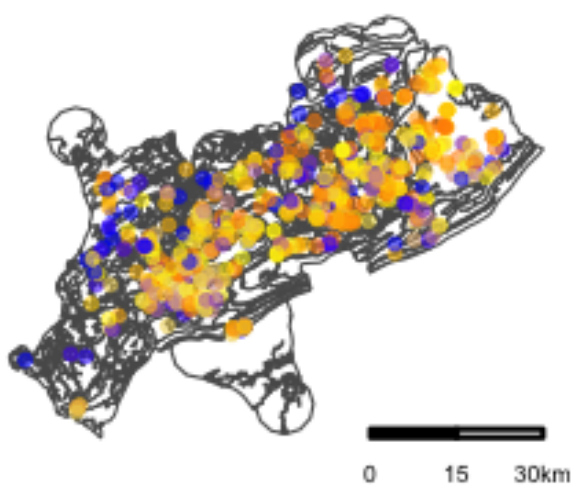

Predicted Depths

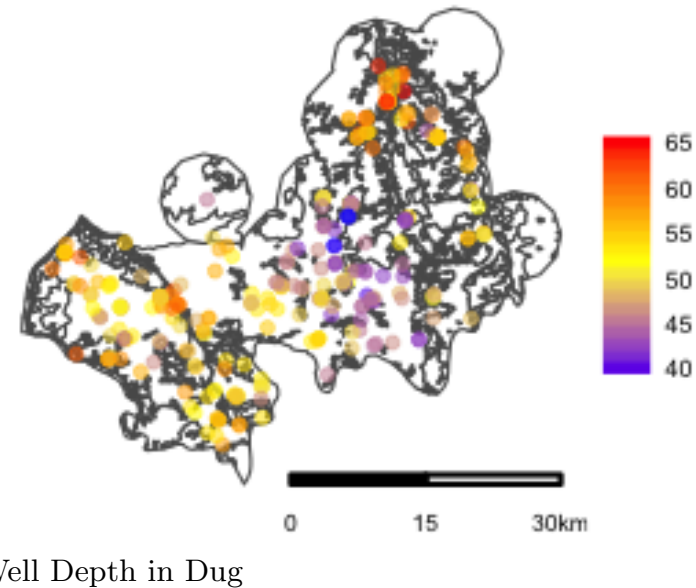

Predicted Depths

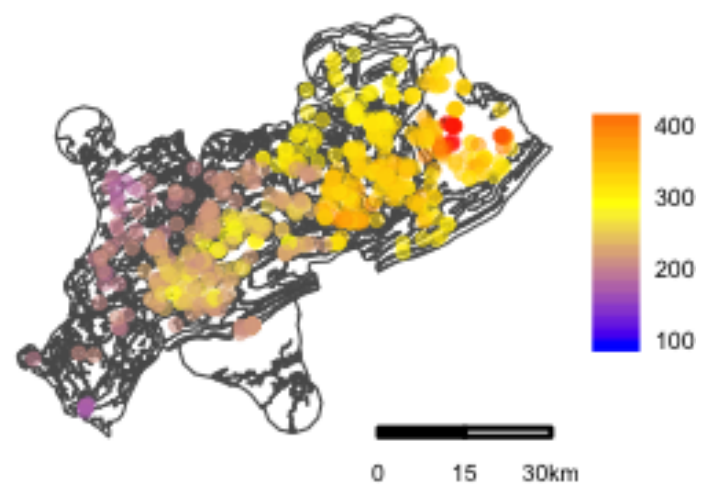

Panel B. Well Depth in Hindoli and Nainwa

True Depths

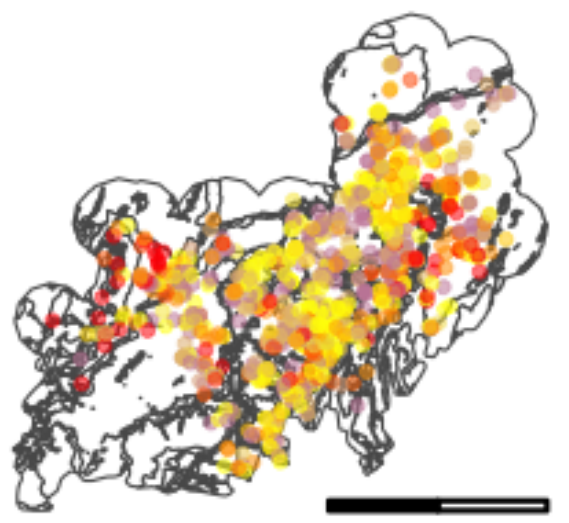

0

Predicted Depths

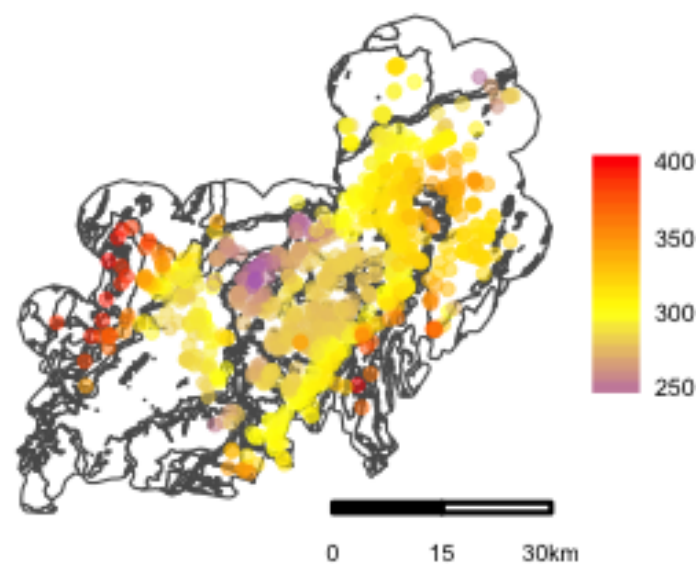

Panel C. Well Depth in Kotputli, Bansur, and Mundawar

The figure shows the variation in well depth for the three groups of subdivisions in our sample. Each panel shows a different area: Dug subdivision (panel A), Hindoli and Nainwa subdivisions (panel B) and Kotputli, Bansur and Mundawar subdivisions (panel C). Within each panel, the map on the left shows the actual depth of wells as reported by farmers, against the scale at right. The map on the right shows the depth of wells that is predicted based on geological factors. The set of geological factors used as instruments is described in Section 2 in brief and Appendix A gives the rationale for these factors. 
Figure 4: Optimality of ration

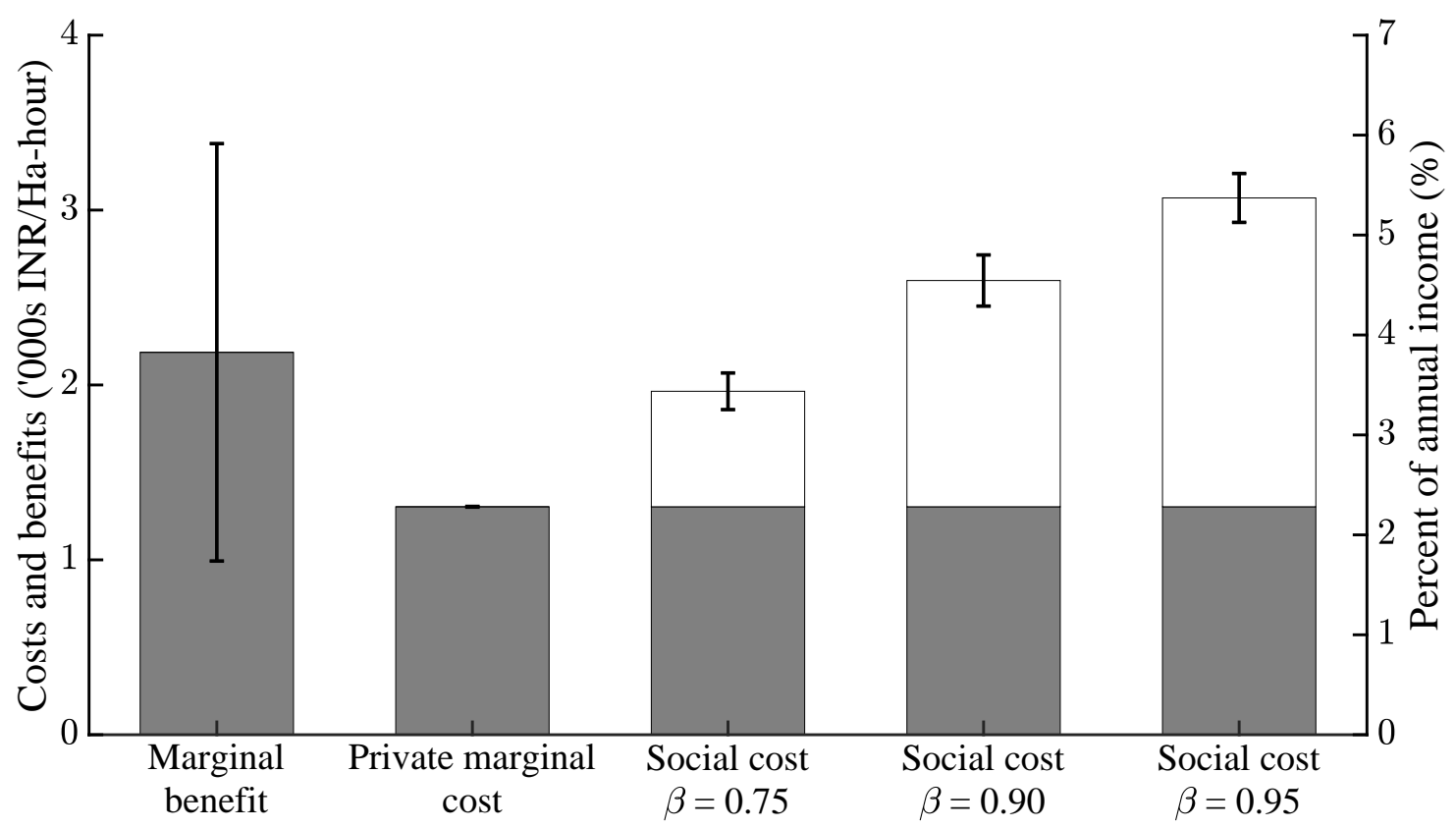

The figure compares the marginal benefit and marginal cost of a one hour increase in the ration on average across all farmers. The estimates come from the marginal analysis presented in Section 4. The marginal benefit is derived from our estimate in Table 2, column 3 using the calculation shown in Table D10, column 1. The marginal cost is similarly calculated in Table D10, column 2. The left-hand axis gives the marginal benefit or cost in units of INR thousand per Ha per hour increase in the ration. The right-hand axis gives the marginal benefit or cost as a percentage of the annual household income of agricultural households. The whiskers show $90 \%$ confidence intervals for each estimate.

Figure 5: Distribution of productivity across farmer-crops

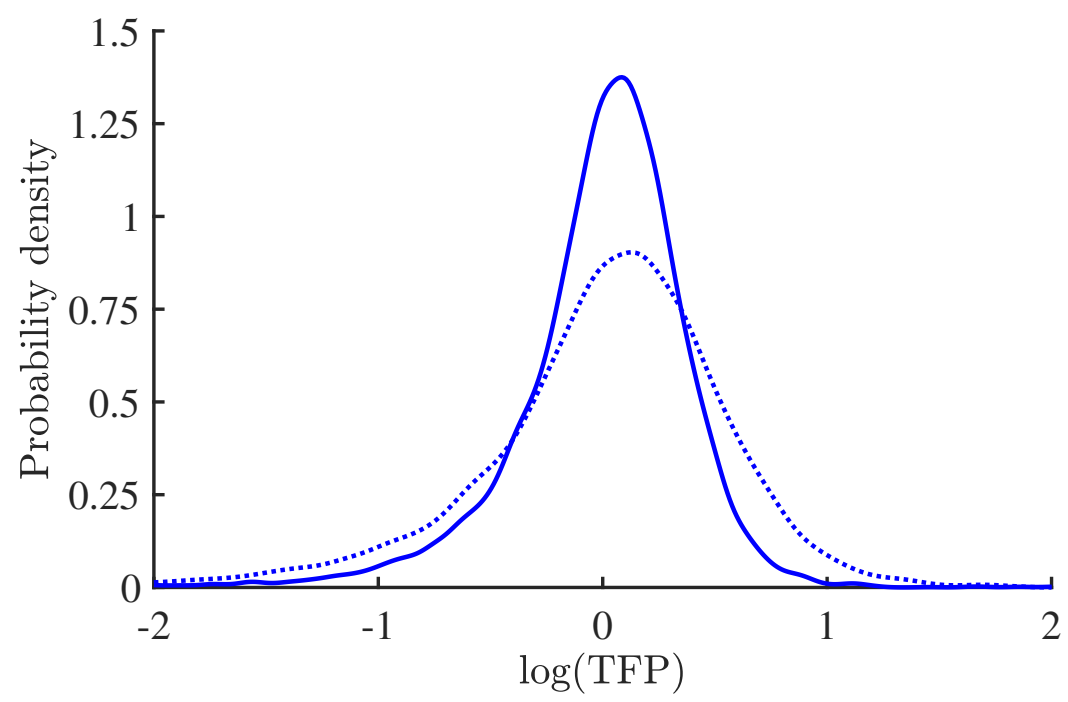

—Deflated to remove measurement error

........ Raw

The figure shows the distribution of productivity from the estimated production function. The dotted line gives the distribution of the raw, total factor productivity residual from estimation of equation 10. The solid line gives the distribution of total factor productivity after correcting for measurement error in output and inputs. 
Figure 6: Shadow cost of the status quo ration

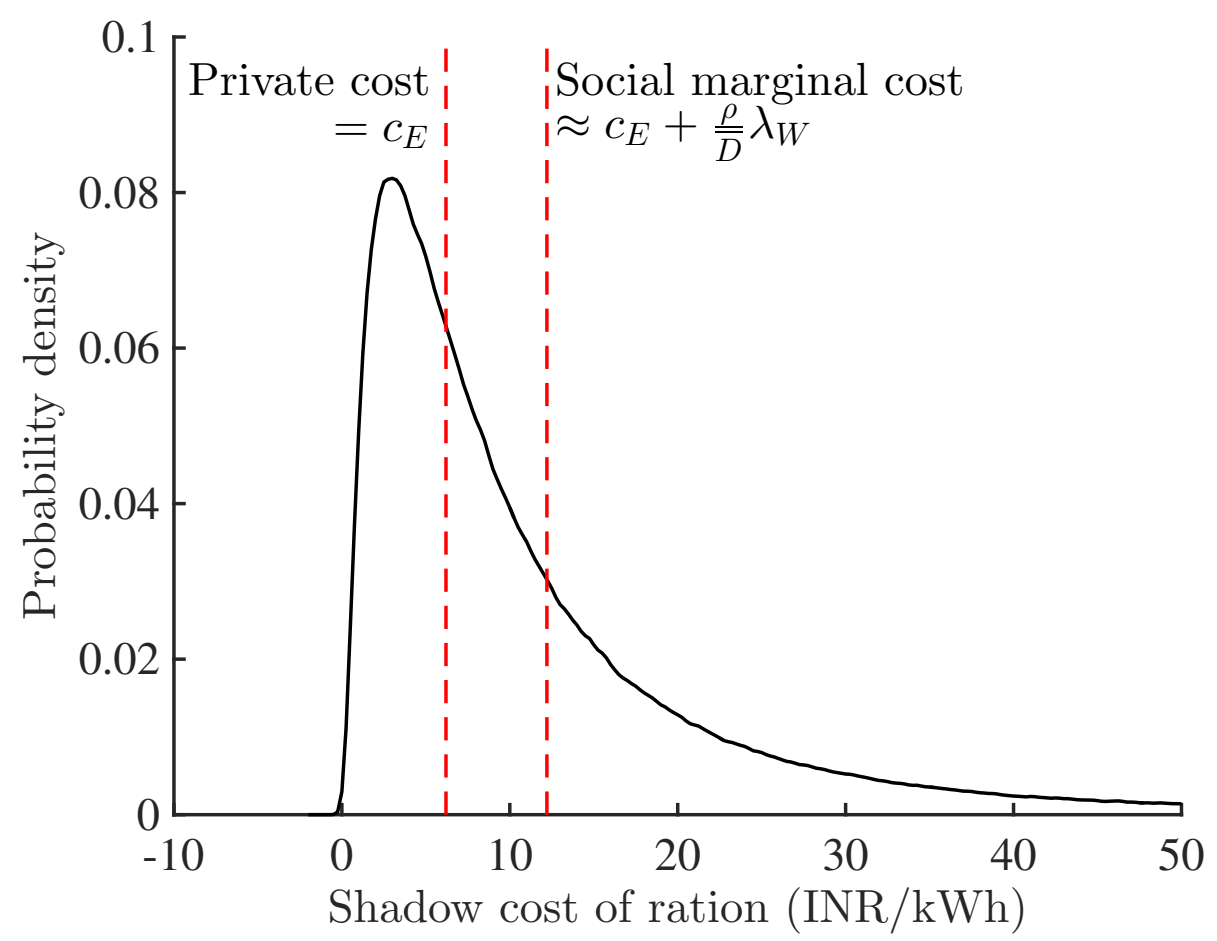

The figure shows the distribution of the shadow cost of the status quo ration, of 6 hours of power per day, across farmer-plots, plus the nominal electricity price of INR 0.9 per $\mathrm{kWh}$. The sum of the shadow cost and the nominal monetary power cost is therefore the overall cost of power faced by each farmer. The shadow cost of the ration gives the marginal benefit of power use and is calculated as the additional price of power that would induce each farmer to use the rationed amount of power on their plot if they were unconstrained. The two dashed vertical lines show benchmarks on the social cost of power use. The line on the left shows the private marginal cost of energy supply $c_{E}=6.2 \mathrm{INR} / \mathrm{kWh}$. The line of the right shows the average social marginal cost of power use, i.e. the Pigouvian price of power. 
Figure 7: Change in Profit Due to Pigouvian Reform by Plot Size

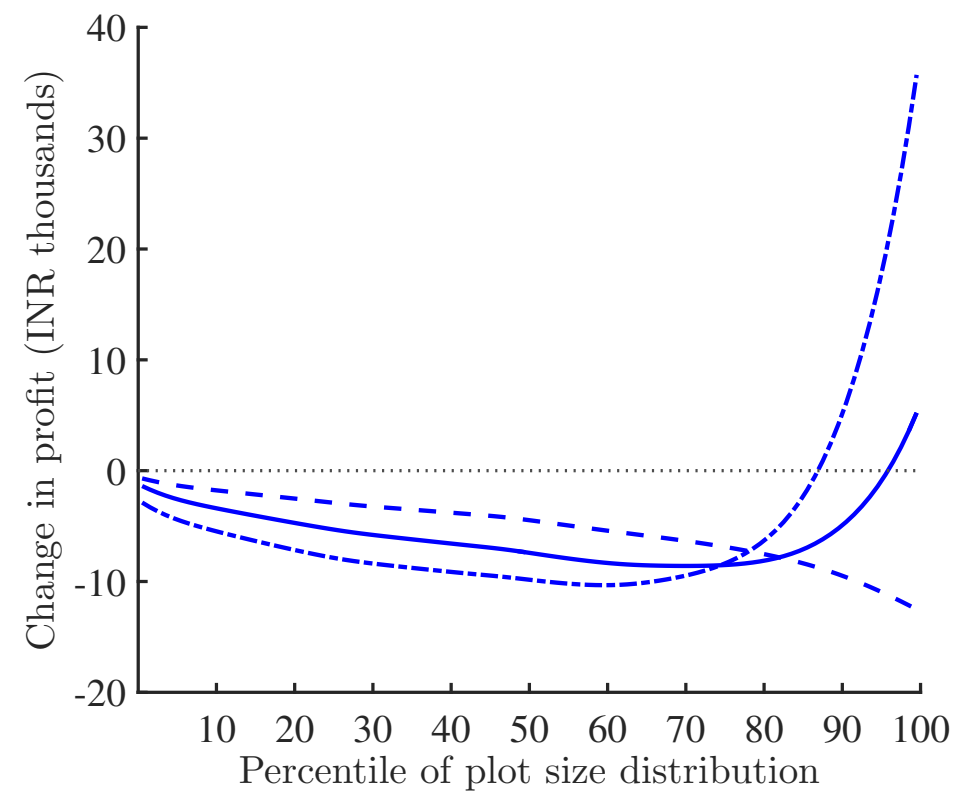

- - Mean change in profit if low productivity (bottom quartile)

---- Mean change in profit if high productivity (top quartile)

- Mean change in profit

The figure shows the mean, across farmers and crops, of the change in profit from a reform that replaces the status quo rationing regime with a Pigouvian regime that prices power at social cost, without any compensating transfers to farmers. A negative value therefore means profits decline under the Pigouvian regime and a positive value that they increase. The three separate curves show the mean change in profit, plotted by plot size, for farmer-crops in the bottom quartile of the productivity distribution (dashed line), the top quartile (dashed and dotted line), and all farmers (solid line). The data is smoothed using a local linear regression. 


\section{Tables}

Table 1

Summary statistics on farmer survey sample

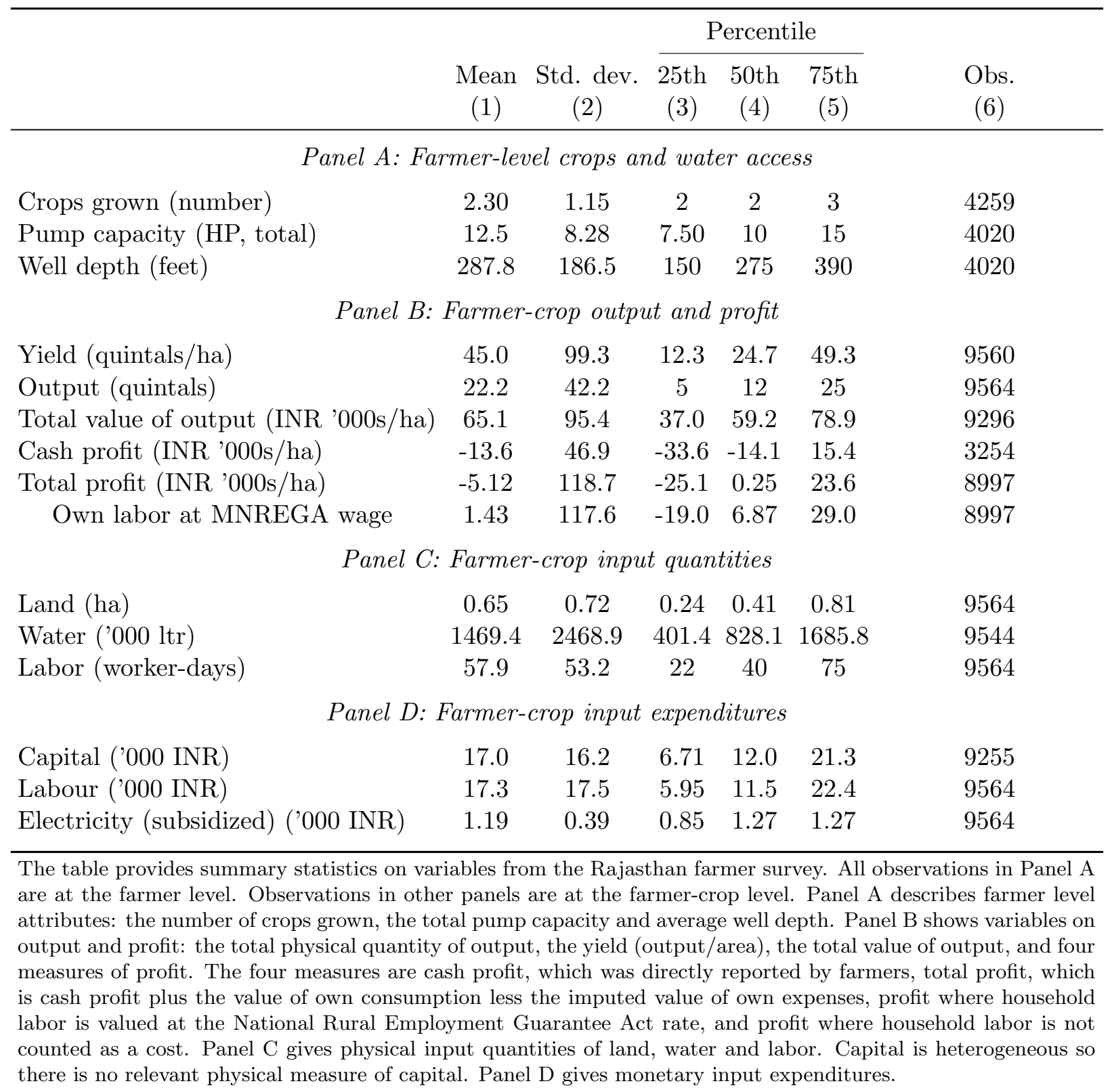


Table 2

Hedonic regressions of profit on well depth

\begin{tabular}{|c|c|c|c|c|}
\hline & $\begin{array}{l}\text { OLS } \\
(1)\end{array}$ & $\begin{array}{l}\text { OLS } \\
(2)\end{array}$ & $\begin{array}{c}\text { IV-PDS } \\
(3)\end{array}$ & $\begin{array}{c}\text { IV-PDS } \\
(4)\end{array}$ \\
\hline \multicolumn{5}{|c|}{ Panel A. Total Profit ('O0O INR per Ha) } \\
\hline Well depth (1 sd = 187 feet $)$ & $\begin{array}{c}0.69 \\
(1.25)\end{array}$ & $\begin{array}{r}-2.71^{*} \\
(1.56)\end{array}$ & $\begin{array}{c}-8.87^{* * *} \\
(2.47)\end{array}$ & $\begin{array}{c}-7.01^{* * *} \\
(2.70)\end{array}$ \\
\hline Toposequence & & Yes & Yes & Yes \\
\hline Soil quality controls & & Yes & Yes & Yes \\
\hline Subdivisional effects & & Yes & Yes & Yes \\
\hline Plot size effects & & Yes & Yes & Yes \\
\hline Mean dep. var & -5.12 & -5.12 & -5.12 & -5.12 \\
\hline Candidate Instruments & & & 419 & 1728 \\
\hline Instruments Selected & & & 14 & 19 \\
\hline Unique Farmers & 4008 & 3999 & 3999 & 3999 \\
\hline Farmer-Crops & 8991 & 8973 & 8973 & 8973 \\
\hline \multicolumn{5}{|c|}{ Panel B. Cash Profit, reported ('000 INR per Ha) } \\
\hline Well depth (1 sd = 187 feet $)$ & $\begin{array}{c}-3.44^{* * *} \\
(0.81)\end{array}$ & $\begin{array}{c}-2.84^{* * *} \\
(1.02)\end{array}$ & $\begin{array}{r}-10.6^{* *} \\
(5.02)\end{array}$ & $\begin{array}{r}-14.7^{* *} \\
(5.87)\end{array}$ \\
\hline Toposequence & & Yes & Yes & Yes \\
\hline Soil quality controls & & Yes & Yes & Yes \\
\hline Subdivisional effects & & Yes & Yes & Yes \\
\hline Plot size effects & & Yes & Yes & Yes \\
\hline Mean dep. var & -13.6 & -13.6 & -13.6 & -13.6 \\
\hline Candidate Instruments & & & 419 & 1728 \\
\hline Instruments Selected & & & 9 & 7 \\
\hline Unique Farmers & 2127 & 2121 & 2121 & 2121 \\
\hline Farmer-Crops & 3253 & 3243 & 3243 & 3243 \\
\hline
\end{tabular}

The table reports coefficients from regressions of agricultural profit measures on well depth and controls. The coefficients represent changes in the outcome variable induced by a one standard deviation increase in the farmer's well depth. The data is from the main agricultural household survey and the observations are at the farmer-by-crop level. The dependent variable changes in each panel. In Panel A, the dependent variable is total profit, which includes the value of the farmer's own consumption (INR per Ha). Where no profit is reported in cash, and the farmer keeps all the output for own consumption, we impute the total profit variable by adding the value of output consumed subtracting the input costs associated with the output. The price used in this imputation for each crop is taken to be the median market price for the crop reported at the SDO level. In Panel B, the dependent variable is reported cash profit (INR per Ha). Well depth is the reported depth of a given farmer's well. Toposequence includes controls for elevation and slope. Subdivisional effects are dummy variables for each of the six sub-divisional offices of the distribution company from which farmers were sampled. Plot size effects are dummy variables indicating the plot size decile for each farmer-crop based on its plot area. Standard errors are clustered at the level of the feeder, the primary sampling unit. The statistical significance of a coefficient at certain thresholds is indicated by ${ }^{*} p<0.10,{ }^{* *} p<0.05,{ }^{* * *} p<0.01$. 
Table 3

Production Function Estimates

\begin{tabular}{|c|c|c|c|c|}
\hline \multirow[t]{2}{*}{ Dependent variable } & \multicolumn{4}{|c|}{$\log$ (Value of output) } \\
\hline & OLS & 2SLS & 2SLS & $2 \mathrm{SLS}$ \\
\hline Endogenous inputs: & $(1)$ & $\begin{array}{c}\text { Water } \\
(2)\end{array}$ & $\begin{array}{l}\text { All } \\
(3)\end{array}$ & $\begin{array}{l}\text { All } \\
(4)\end{array}$ \\
\hline $\log ($ Water $)$ & $\begin{array}{l}0.04^{* * *} \\
(0.010)\end{array}$ & $\begin{array}{l}0.18^{* * *} \\
(0.063)\end{array}$ & $\begin{array}{r}0.15^{* *} \\
(0.060)\end{array}$ & $\begin{array}{l}0.18^{\text {*** }} \\
(0.044)\end{array}$ \\
\hline $\log ($ Land $)$ & $\begin{array}{l}0.54^{* * *} \\
(0.040)\end{array}$ & $\begin{array}{l}0.49^{* * *} \\
(0.047)\end{array}$ & $\begin{array}{l}0.51^{* * *} \\
(0.057)\end{array}$ & $\begin{array}{l}0.51^{* * *} \\
(0.059)\end{array}$ \\
\hline $\log ($ Labor $)$ & $\begin{array}{l}0.16^{* * *} \\
(0.025)\end{array}$ & $\begin{array}{l}0.12^{* * *} \\
(0.030)\end{array}$ & $\begin{array}{r}0.24 \\
(0.157)\end{array}$ & $\begin{array}{r}0.24 \\
(0.180)\end{array}$ \\
\hline $\log ($ Capital $)$ & $\begin{array}{l}0.34^{* * *} \\
(0.032)\end{array}$ & $\begin{array}{l}0.34^{* * *} \\
(0.033)\end{array}$ & $\begin{array}{r}0.30^{* *} \\
(0.150)\end{array}$ & $\begin{array}{r}0.30^{*} \\
(0.168)\end{array}$ \\
\hline Toposequence & Yes & Yes & Yes & Yes \\
\hline Soil quality & Yes & Yes & Yes & Yes \\
\hline Subdivisional effects & Yes & Yes & Yes & Yes \\
\hline Mean dep. var & 3.24 & 3.24 & 3.24 & 3.24 \\
\hline Farmers & 3998 & 3998 & 3998 & 3998 \\
\hline Farmer-crops & 8711 & 8711 & 8711 & 8711 \\
\hline
\end{tabular}

The table reports estimates of the production function. The dependent variable is the log of the total value of agricultural output. The independent variables are the logs of productive inputs, water, land, labor and capital, as well as exogenous control variables. All specifications include as controls subdivision fixed effects, as described in the notes of Table 2, toposequence variables for elevation and slope, and soil quality measured at the village level (acidity/alkalinity of the soil along with variables measuring the level of eight minerals). The columns vary in the method of estimation and what variables are treated as endogenous. Column 1 shows OLS estimates. Column 2 shows instrumental variables estimates treating only water as endogenous and using as instruments only geological factors. Column 3 shows instrumental variables estimates treating all four inputs as endogenous. The first stage results for the column 3 specification are reported in Appendix C, Table C7. Column 4 takes the column 3 estimates and calibrates the elasticity of output with respect to water to match the marginal benefit of relaxing the ration by one hour, as reported in Table D10, column 1, panel A. Columns 1 to 3 report analytic standard errors clustered at the level of the feeder, the primary sampling unit. Column 4 reports cluster-bootstrapped standard errors, also clustered at the feeder level, to account for uncertainty in the estimated marginal benefit of relaxing the ration. Statistical significance is indicated by ${ }^{*} p<0.10,{ }^{* *} p<0.05,{ }^{* * *} p<0.01$. 
Table 4

Counterfactual Production and Social Surplus

\begin{tabular}{|c|c|c|c|c|}
\hline & \multicolumn{2}{|c|}{ Rationing } & \multicolumn{2}{|c|}{ Pricing } \\
\hline & $\begin{array}{l}\text { Status quo } \\
(1)\end{array}$ & $\begin{array}{l}\text { Optimal } \\
(2)\end{array}$ & $\begin{array}{c}\text { Private cost } \\
(3)\end{array}$ & $\begin{array}{c}\text { Pigouvian } \\
\text { (4) }\end{array}$ \\
\hline \multicolumn{5}{|c|}{ A. Profits and social surplus } \\
\hline Profit (INR 000s) & 20.83 & 19.15 & 21.85 & 15.11 \\
\hline - Unpriced power cost (INR 000s) & 5.36 & 4.46 & 0.00 & -4.85 \\
\hline - Water cost (INR 000s) & 5.33 & 4.43 & 9.56 & 5.19 \\
\hline Surplus (INR 000s) & 10.13 & 10.26 & 12.29 & 14.77 \\
\hline \multicolumn{5}{|c|}{ B. Input use } \\
\hline Land (Ha) & 0.69 & 0.69 & 0.69 & 0.69 \\
\hline Labor (person-days) & 54.81 & 54.81 & 54.81 & 54.81 \\
\hline Capital (INR 000s) & 16.31 & 15.53 & 20.51 & 17.68 \\
\hline Water (liter 000s) & 1592.37 & 1322.45 & 2853.76 & 1548.15 \\
\hline Power (kWh per season) & 1011.60 & 840.86 & 1572.73 & 806.97 \\
\hline Hours of use (per day) & 5.96 & 4.95 & 10.99 & 6.12 \\
\hline \multicolumn{5}{|c|}{ C. Output and productivity } \\
\hline Output (INR 000s) & 54.61 & 52.00 & 68.67 & 59.21 \\
\hline Gain in output from status quo (pp) & & -5 & 26 & 8 \\
\hline Gain in output due to input use (pp) & & -5 & 19 & 2 \\
\hline Gain in output due to productivity (pp) & & -0 & 7 & 6 \\
\hline $\operatorname{Cov}\left(\Omega_{E i t}, W_{i t}^{\alpha_{W}}\right)$ & -0.04 & -0.04 & 0.23 & 0.24 \\
\hline
\end{tabular}

The table shows the outcomes of counterfactual policy regimes with respect to farmer profit, external costs and social surplus. The columns show different policy regimes: the status quo rationing regime, with a ration of 6 hours and a price of INR 0.90 per $\mathrm{kWh}$, a private cost regime, where power is priced at its private marginal cost of INR 6.2 per $\mathrm{kWh}$, and a Pigouvian regime where power is priced at marginal social cost. The rows show the outcome variables in each regime. All outcome variables, except where noted, are mean values at the farmer-by-crop level, where the average farmer plants 2.3 crops. Panel $\mathrm{C}$ shows output and the change in output, in percentage points, relative to the status quo value under rationing. Row 3 gives the change in output that would have been achieved from a proportional change in input use for all farmers, equal to the aggregate proportional change in input use in each scenario relative to column 1. Row 4 then gives the residual change in output due to increases in aggregate productivity from the input reallocation. Finally, row 5 reports the covariance between $\Omega_{E i t}$ and the contribution of water input to production. 
Table 5

Distributional Effects of Pigouvian Reform

\begin{tabular}{|c|c|c|c|c|c|}
\hline \multirow[b]{2}{*}{ Transfers: } & \multirow{2}{*}{$\begin{array}{c}\text { Rationing } \\
\text { None } \\
(1)\end{array}$} & \multicolumn{4}{|c|}{ Pigouvian } \\
\hline & & $\begin{array}{c}\text { None } \\
(2)\end{array}$ & $\begin{array}{l}\text { Flat } \\
(3)\end{array}$ & $\begin{array}{c}\text { Pump } \\
(4)\end{array}$ & $\begin{array}{l}\text { Land } \\
(5)\end{array}$ \\
\hline \multicolumn{6}{|c|}{ A. Inequality under different transfer schemes } \\
\hline Mean profit (INR 000s) & 45.36 & 32.90 & 32.90 & 32.90 & 32.90 \\
\hline + Mean transfer (INR 000s) & 0.00 & 0.00 & 22.24 & 22.24 & 22.24 \\
\hline Mean net profit (INR 000s) & 45.36 & 32.90 & 55.13 & 55.13 & 55.13 \\
\hline Std dev net profit (INR 000s) & 75.06 & 83.38 & 85.24 & 86.64 & 88.97 \\
\hline \multicolumn{6}{|c|}{ B. Change from rationing regime due to reform } \\
\hline Share who gain & & 0.10 & 0.74 & 0.68 & 0.61 \\
\hline \multicolumn{6}{|l|}{ Conditional on gain in profit: } \\
\hline Mean ex ante profit & & 139.63 & 38.29 & 42.21 & 45.67 \\
\hline Mean change in net profit & & 26.65 & 17.33 & 19.46 & 23.51 \\
\hline Mean land $(\mathrm{Ha})$ & & 3.43 & 1.45 & 1.51 & 1.63 \\
\hline Mean depth (feet) & & 212.21 & 277.48 & 294.46 & 274.06 \\
\hline Mean productivity (percentile) & & 55.17 & 46.69 & 49.56 & 45.78 \\
\hline Share who lose & & 0.90 & 0.26 & 0.32 & 0.39 \\
\hline \multicolumn{6}{|l|}{ Conditional on loss in profit: } \\
\hline Mean ex ante profit & & 35.11 & 65.94 & 51.91 & 44.88 \\
\hline Mean change in net profit & & -16.71 & -12.22 & -10.42 & -11.46 \\
\hline Mean land (Ha) & & 1.30 & 1.67 & 1.51 & 1.33 \\
\hline Mean depth (feet) & & 296.11 & 318.21 & 274.16 & 309.27 \\
\hline Mean productivity (percentile) & & 49.99 & 61.60 & 52.47 & 57.80 \\
\hline
\end{tabular}

The table shows the distributional impacts of Pigouvian reform on farmer profits. The columns show results for different policy regimes: column 1 is the status quo rationing regime and columns 2 through 4 show regimes with Pigouvian pricing. The Pigouvian regimes differ in the transfers made to farmers and how those transfers are conditioned. In column 2 onwards, the transfer policies are: no transfers, flat (uniform) transfers, transfers pro rata based on pump capacity, and transfers pro rata based on land size. The rows in Panel A show summary statistics on the level of profits under different regimes. The rows in Panel B show summary statistics on the changes in profits between the status quo rationing regime (column 1) and the respective Pigouvian regimes (columns 2 through 5) 